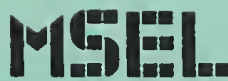

Materials Science and Engineering Laboratory

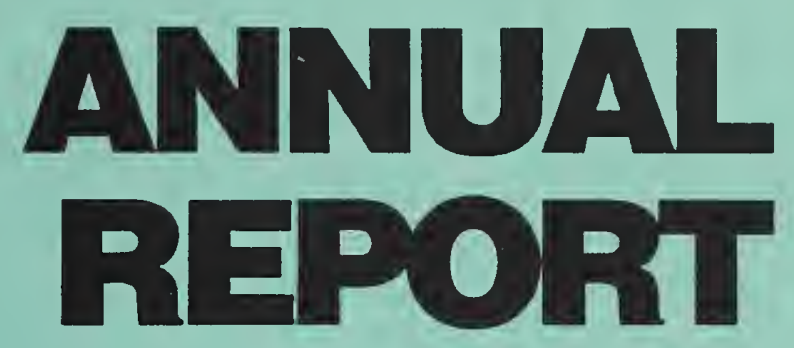

1990

NAS-NRC

Assessment Panel January 31-

February 1, 1991
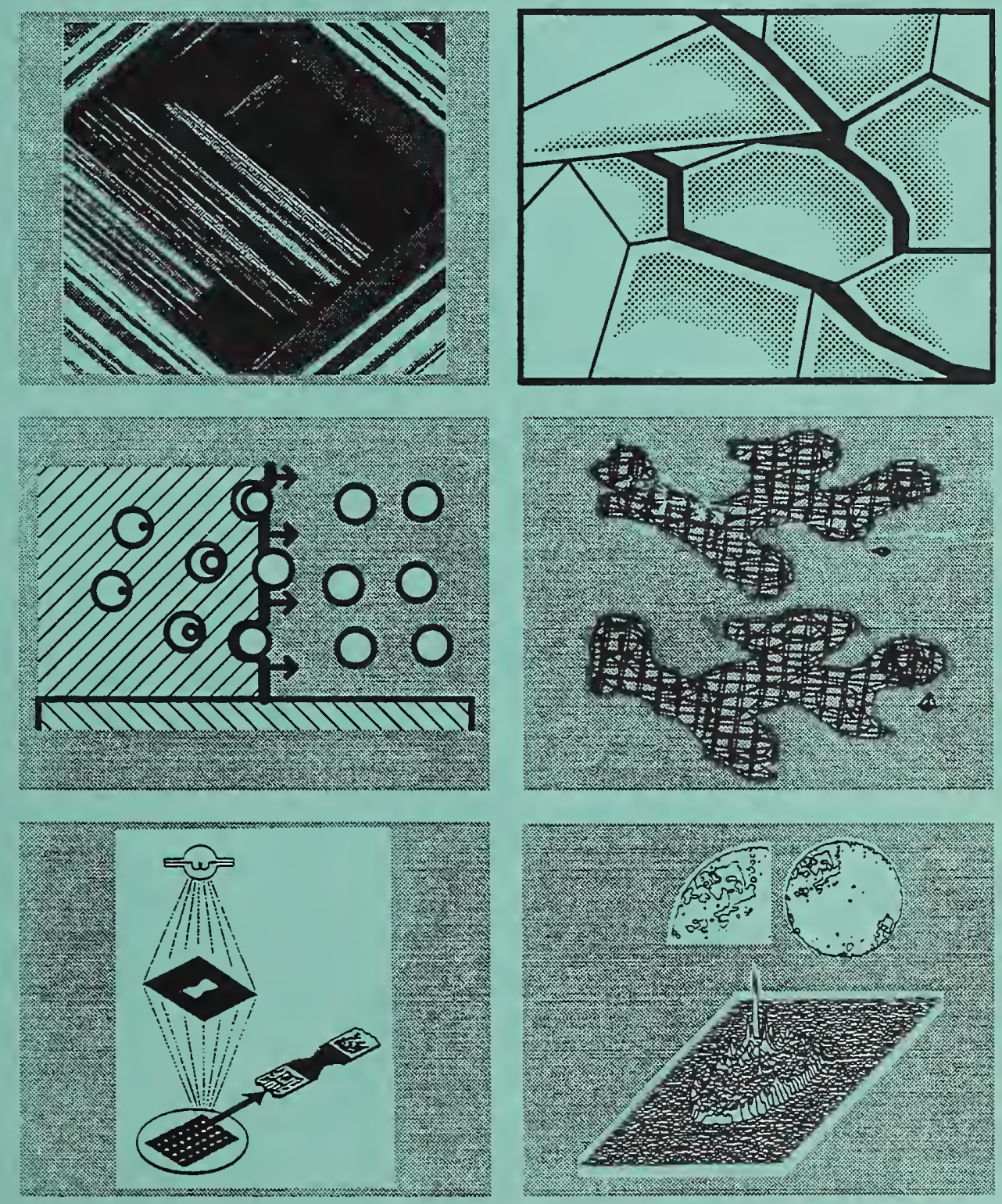

NISTIR 90-4392 U.S. Department of Commerce

National Institute of Standards and Technology 
Annual report covers for the operating divisions of the Materials Science and Engineering Laboratory and its Office of Nondestructive Evaluation. These annual reports describe in detail the technical activities of each of the Laboratory's major units and are available on request. 
Materials Science and Engineering Laboratory

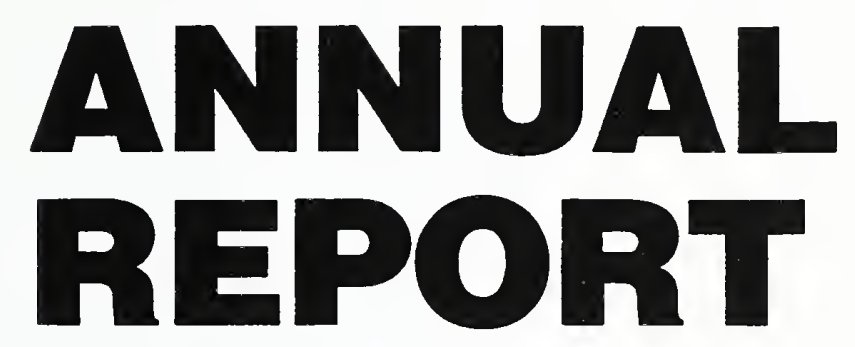

NAS-NRC

Assessment Panel

January 31-February 1, 1991

NISTIR 4392

U.S. Department of Commerce

National Institute of Standards

and Technology

\section{Technical Activities 1990}

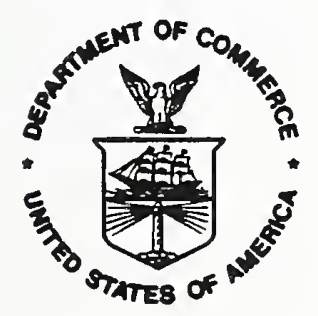





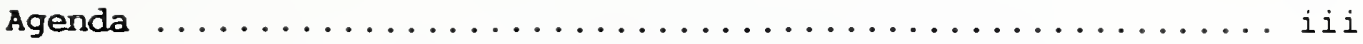

office of the Director $\ldots \ldots \ldots \ldots \ldots \ldots \ldots \ldots \ldots \ldots \ldots$ vii

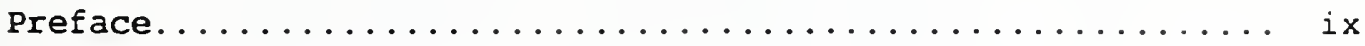

OVERVIEW. . . . . . . . . . . . . . . . . . . . . . . 13

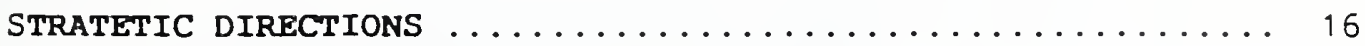

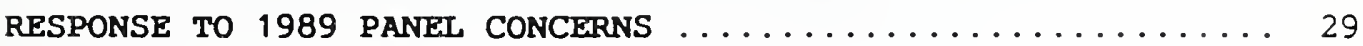

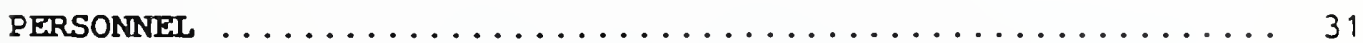

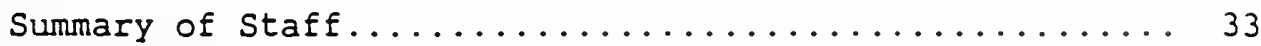

FY 1990 NRC-NAS Postdoctorals................ 34

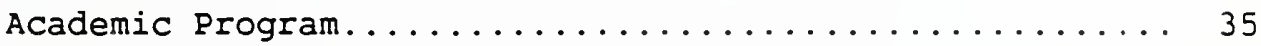

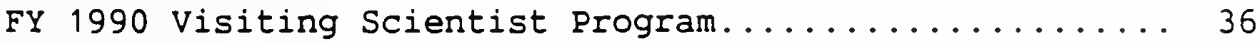

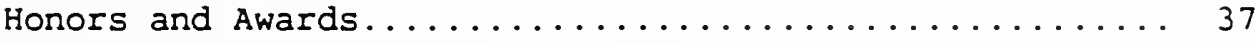

TECHNOLOGY TRANSFER $\ldots \ldots \ldots \ldots \ldots \ldots \ldots \ldots \ldots \ldots \ldots \ldots \ldots \ldots$

Conference Program...................... 47

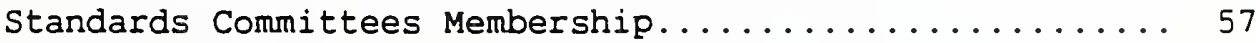

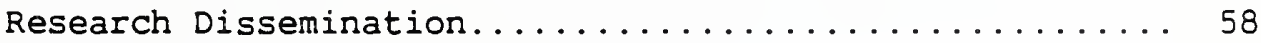

Patents, SRMs and Data Monographs................ 59

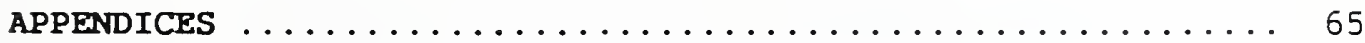

A. 1990 Panel Members..................... 67

B. An Evaluative Report on the Institute for

Materials Science and Engineering (1990).......66 69

C. NIST Organizational Chart................... 87

D. MSEL Organizational Chart................ 88

E. MSEL Functional Statement................... 89 

FINAL AGENDA

BOARD OF ASSESSMENT PANEL OF NIST PROGRAMS

FOR THE MATERIALS SCIENCE AND ENGINEERING LABORATORY (MSEL)

\section{Wednesday, January 30,1991}

8:00 p.m. Panel Orientation Meeting at the Compri Hotel (L. H. Schwartz, H. L. Rook, D. B. Butrymowicz, S. J. Schneider, J. G. Early, and Panel Members), and Charge to Panel

Thursday, January 31,1991

8:00 a.m. Panel meets Compri van in front of Compri Hotel for ride to Administration Building, NIST

\section{Lecture Room A, Adminstration Building}

8:15 a.m. Coffee and Donuts

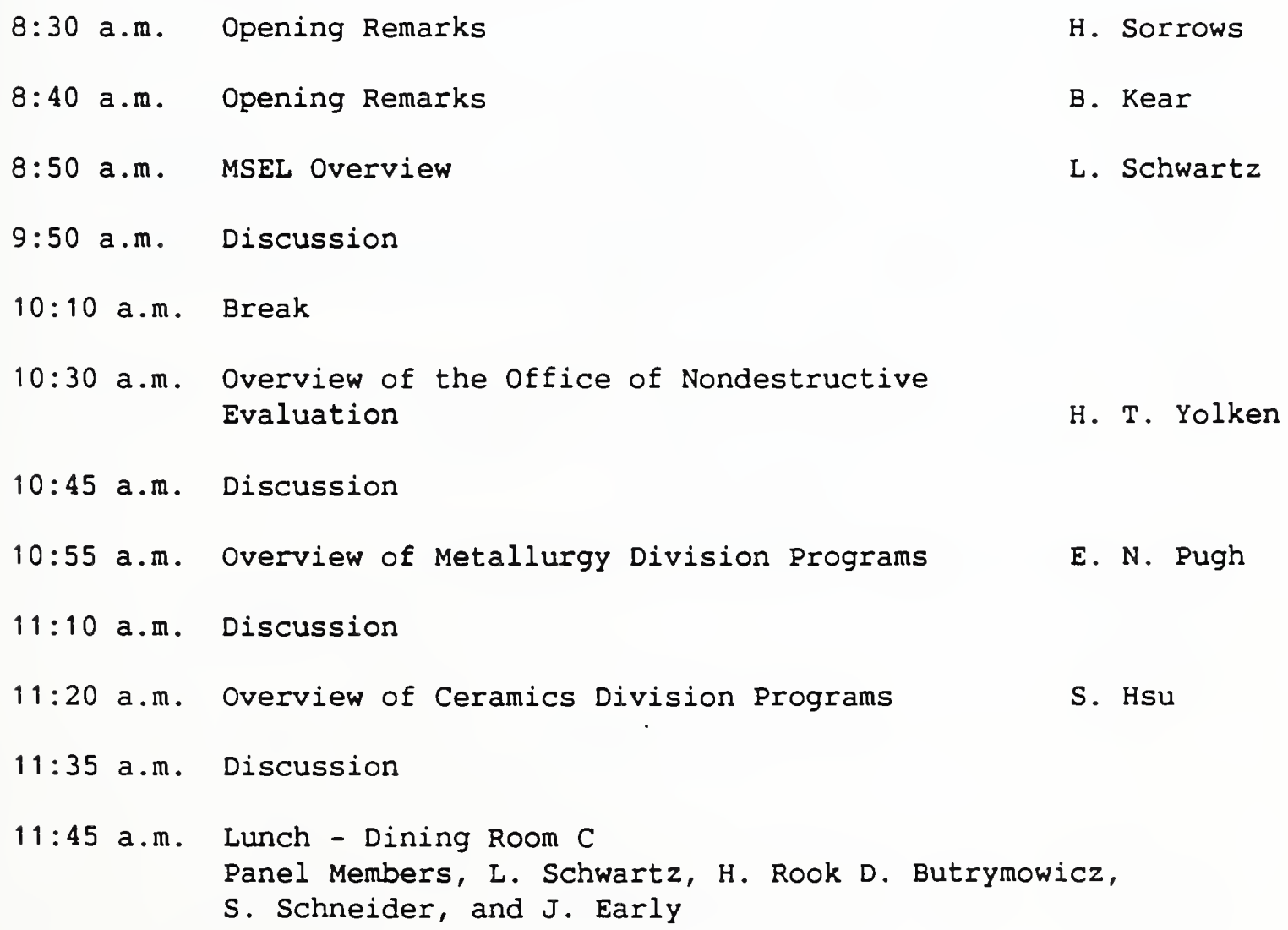




\section{Lecture Room B}

12:45 p.m. Poster Presentations on Laboratory Research

- Thermal Neutron Reflectometry Studies of Polymer and Magnetic Thin Films - C. J. Majkrzak, S. Satija, and J. Ankner

- Maximum Entropy Methods for Biological Crystallography E. Prince

- Structure and Magnetic Properties of New Rare Earth and Magnetic Semiconductor Multilayers - R. Erwin, J. Borchers, and $T$. Giebultowicz

- Glass Transition Temperatures of Polymer Blends - E. A. DeMarzio

- Shear Effect in Phase Behavior of Polymer Blends Studied by SANS and Light Scattering - C. C. Han, A. I. Nakatani, and D. A. Waldow

- Flow Through Porous Media - F. R. Phelan and R. S. Parnas

- Surface Forces - R. Horn

- SANS and X-Ray Analysis of Sintering - G. Long

- Magnetic Properties of Nanocomposites - R. ShuIl and L. Bennett

- Phase Equilibria and Transformation Paths in Ti-Al-Nb Ordered Intermetallic Alloys - W. Boettinger, L. Bendersky, and B. Burton

- Quasicrystals - J. Cahn and F. Gayle

- Applications of Green's Functions to Problems in Materials Science - V. K. Tewary, R. Thomson, and C. M. Fortunko

\section{Lecture Room A}

1:45 p.m. Overview of Materials Reliability Division Programs

H. McHenry

2:00 p.m. Discussion

2:10 p.m. Overview of Polymers Division Programs

L. Smith

$2: 25$ p.m. Discussion

2:35 p.m. Overview of Reactor Radiation Division Programs

\section{$2: 50$ p.m. Discussion}

3:00 p.m. Travel to Reactor 
3:15 p.m. Tour of Cold Neutron Research Facility

4:15 p.m. Travel to Administration Building, Lecture Room A

4:30 p.m. Executive Session with MSEL Director (coffee and soda available)

5:30 p.m. Panel meets Compri van in front of Materials Building for ride to Compri Hotel

6:15 p.m. Panel meets NIST van in front of Compri Hotel for ride to Golden Bull Restaurant

6:30 p.m. Social Hour and Dinner - Golden Bull Restaurant. Division Chiefs, L. Schwartz, H. Rook, D. Butrymowicz, S. Schneider, and J. Early

9:30 p.m. Panel members ride back to Compri Hotel with Division Chiefs 
8:00 a.m. Panel meets Compri van in front of Compri Hotel for ride to Administration Building, NIST

\section{Dining Room $C$}

8:30 a.m. Executive Session (Panel Only)

Coffee and donuts available before and during the executive session

12:00 p.m. Lunch with Division Chiefs and L. Schwartz, H. Rook, D. Butrymowicz, S. Schneider, and J. Early (Dining Room C)

1:00 p.m. Panel Chairman meets with L. Schwartz and H. Rook Materials Building, Room B304

1:15 p.m. Panel meets Compri van in front of Administration Building for ride to Compri Hotel

2:00 p.m. Panel Chairman meets with John W. Lyons, Director, NIST Administration Building, Room A1134

Panel members have an open schedule after lunchtime on Friday, Feb. 1.

Panel members requiring special arrangements to airport on Friday, February 1, should contact Dan Butrymowicz/Linda Leaman on Thursday, January 31. 


\section{OFFICE OF THE DIRECTOR \\ MATERIALS SCIENCE AND ENGINEERING LABORATORY}

DIRECTOR

Lyle H. Schwartz

(301) 975-5658

DEPUTY DIRECTOR

Harry L. Rook

(301) 975-5658

SCIENTIFIC ADVISORS

Daniel B. Butrymowicz

(301) 975-5656

Samuel J. Schneider

(301) 975-5657

James G. Early

(301) 975-6113

ADMINISTRATIVE OFFICERS

Paul M. Fleming

(301) 975-5653

Deborah J. Anderson

(301) 975-5654 



\section{PREFACE}

The National Academy of Sciences-National Research Council (NAS-NRC) Board on Assessment of NIST Programs, and in particular, the Panel for Materials Science and Engineering, performs an important role in the programs and success of the Materials Science and Engineering Laboratory (MSEL). The Panel is one of our most effective means for assuring a continuous interaction between our staff and counterparts in the scientific and engineering communities of U.S. industry and academe. Each of the Panel members is selected by the National Research Council on the basis of expertise and extensive experience in the areas of research and technology conducted by the Laboratory. In addition to this Laboratory-wide Panel, we also have an Evaluation Panel for the Reactor Radiation Division.

The 1990 Annual Report was prepared for the NAS-NRC Board of Assessment of the MSEL. The Report contains background information on resources, activities, and representative highlights of the Laboratory. For the first time, this report also includes a brief statement of the strategic plan of MSEL, our contribution to the ongoing planning exercise in which NIST is engaged. A second series of reports on detailed technical accomplishments are published separately as National Institute of Standards and Technology Internal Reports (NISTIR) for each Division/Office. These reports are available to members reviewing individual Divisions.

We look forward to your input and advice in both the evaluation and formulation process of our management decisions at all levels in the Laboratory. During this last year, I know that you have spent time in visiting our Laboratory and discussing programs, progress and plans with our staff. I appreciate the time that you give and look forward to working with you in the future.

Lyle H. Schwartz

December 26, 1990 

OVERVIEW 



\section{OVERVIEW}

The Materials Science and Engineering Laboratory (MSEL) is responsible for providing the Nation with measurement methodology and technology, standards, concepts, reference materials, critically evaluated data, and other technical information on the fundamental aspects of processing, structure, properties, and performance of materials. These outputs are directed to the needs of U.S. industry, government agencies, academic institutions, and other scientific and technical organizations. The programs of MSEL support a wide base of generic technologies in materials, in order to provide for their safe, efficient, and economical use in service. The research activities of the Laboratory address the science base underlying both advanced materials and conventional materials technologies, together with the associated measurement methodology.

The Laboratory consists of five technical division: Ceramics, Materials Reliability (located at the Boulder, Colorado laboratories), Metallurgy, Polymers, and Reactor Radiation; and one independent office, Nondestructive Evaluation, which sponsors cross-cutting research throughout NIST. The MSEL budget in FY 1990 was approximately $\$ 50$ million, including capital equipment acquisitions. MSEL has a staff of 387 , of which 89 percent are in scientific or technical support positions. Seventy percent of our scientists and engineers have Ph.D. degrees. The average age of our full-time scientist and engineer staff has been maintained at 46 years, the same as in 1989 and 1988 and reflects the continuing dynamics of the MSEL technical staff.

In addition to the NIST staff, we had 459 visiting scientists and engineers during 1990 involved in collaborative research or utilization of our special facilities (e.g. research reactor). These visitors represented U.S. industry, academe, other Federal agencies, and foreign institutions. Their stay at MSEL ranged from weeks to the entire year, and their salaries and associated costs were covered by the sponsor organization. These non-NIST researchers provide significant leverage of MSEL staff and resources.

II. Major Organizational and Programmatic Events

Continuing the trend of recent years, 1990 was another year of significant change for the staff of the National Institute of Standards and Technology (NIST) and for the members of the Materials Science and Engineering Laboratory (MSEL). On February 9, 1990, the U.S. Senate confirmed the appointment of Dr. John W. Lyons, former director of the NIST National Engineering Laboratory (NEL), as the ninth director of NIST, formerly the National Bureau of Standards. During his confirmation hearing, Dr. Lyons made the commitment that NIST should not only continue its strong research program in measurement technology necessary to support quality assurance programs in industry, but should increase its emphasis on generic research in newly emerging technologies. 
The Laboratory has continued to expand facilities and research opportunities in spite of the absence of new initiative funding for the last two fiscal years, 1989 and 1990. Installation of special isolation shutters and neutron guides through the reactor confinement building wall and the guide segments within the confinement building was completed for the first three beam-lines in the Cold Neutron Research Facility (CNRF). The rapid pace of instrument development for the CNRF has been maintained and six instruments are expected to be operational by early 1991. These instruments include: an 8-m Small Angle Neutron Scattering (SANS) facility to be operated by the NIST/MSEL Polymers Division; a diffuse scattering time-of-flight spectrometer; the $30-\mathrm{m}$ SANS jointly developed by NIST, Exxon, and the University of Minnesota; the cold neutron depth-profiling facility; the new cold neutron prompt-gamma activation analysis station; and the fundamental neutron physics station. Working with first year funding (FY 1988) from the high performance composites initiative, the polymer composites program has continued to evolve and develop. The twofold program objective is to provide industry with generic science and technology first to, monitor, understand, model, and ultimately control the chemical and physical changes occurring during processing in order to achieve more rapid and reliable fabrication, and second, to establish the processing-microstructure-property relationship needed to improve performance and performance prediction. The program is divided into three task areas: Processing Science; Microstructure Characterization; and Laminate Properties. Recent activities in the Processing Science Task focused on four areas: sponsorship of an Industry Workshop on Polymer Composite Processing; development of a composite fabrication facility; continuation of research on process monitoring; and expansion of a program on resin transfer molding.

Programmatic objectives of these and other core programs of the Laboratory have been reviewed by the individual Divisional subpanels and executive summaries of their findings are presented in this report as an overview for all panel members. Selected highlights of this year's programs follow in a summary format. These highlights are representative of Laboratory programs but are not meant to be all-inclusive. A more comprehensive review of the individual Division's programmatic outputs are given in the Divisions' Annual Reports.

The prospects for 1991 represent a real change from the past several years. Significant new and expanded programs in polymer blends, high performance composites, and intelligent processing of materials (IPM) have received new support reflecting the recognized importance of materials in developing new technologies. After a competitive evaluation process, the NIST Director selected an MSEL proposal to develop a. new scientific competence in the area of characterization of interfacial properties and their effect on the stability and processing of polymer blends. Successful competence proposals receive five year commitments of financial support to establish areas of excellence in science and technology contributing to the NIST mission. A second year funding increment (FY 1991) is now assured for the polymer composites initiative that will accelerate initial efforts directed at microstructure characterization, especially of the resin/fiber interface, and performance prediction through test method development, modeling, and failure mechanism identification. For several years, MSEL has taken the lead in focusing industry and government attention on using in-situ sensing and a 
computer-based approach combining data, process modeling, and expert system to control evolution of materials microstructures, or intelligent processing of materials, through a series of industry-led workshops that identified research needs and opportunities. Building on the recent successfully completed threeyear MSEL/Industry consortium program on the application of these concepts to the inert gas atomization of metal powders, a new programmatic initiative in Intelligent Processing of Materials has received its first funding increment.

The Laboratory now has reached the culmination of a multi-year effort leading to the major re-direction of materials research activities at NIST and a substantial increase in MSEL collaborations with U.S. industry. Over the past six years, new program elements have been developed, funding secured, and put in place that impact a wide spectrum of materials science and engineering. These changes include: competence development programs in advanced neutron methods, metal matrix composites, and polymer blends; doubling the power of the NIST research reactor, development of the CNRF and the transition from construction to instrument development and research; and program initiatives in advanced ceramic materials, high performance composite materials, high temperature superconductors, and intelligent processing of materials. These successfully implemented program elements were responsive to the three major shifts in U.S. materials technology: (1) from commodity materials to advanced materials; (2) Research \& Development leadership from materials producers to materials users; and ( 3 ) from traditional processing concepts to intelligent processing.

The Laboratory now finds itself at a crossroads defined by the end of one planning/implementation phase, initial thoughts about future program directions, and a retrospective look at the past six years. Coincidently and external to MSEL, a series of events associated with planning for materials science and engineering has occurred, and MSEL is well positioned to contribute to and take advantage of these activities in the development of its blueprint for the future. These events include: initiation by the new NIST director of the development of a NIST strategic plan, the completion, public presentation and discussion of the National Research Council (NRC) report on the field of materials, "Materials Science \& Engineering of the 1990s: Maintaining Competitiveness in the Age of Materials", and the Office of Science and Technology Policy/Committee on Materials (OSTP/COMAT) effort to establish a comprehensive database on materials R\&D activities to guide the development of a national materials research plan to implement the NRC report recommendations. A draft document outlining the MSEL vision for the 1990s, titled Strategic Directions, has been prepared and included in this report in order to stimulate discussion among the panel members, Division chiefs, and the Laboratory management. 
Not For Distribution

\title{
STRATEGIC DIRECTIONS
}

\section{Materials Science and Engineering Laboratory}

\author{
November 1990
}

\begin{abstract}
Materials are the keystone building blocks of modern society; they are central to the reliable and efficient functioning of engineering structures, components, devices, and machines and thus technological progress in such diverse fields as electronics, construction, energy, communications, and transportation hinges on the development of materials with properties and performance characteristics far superior to materials used today. The functioning of devices and machines is often more limited by their component materials than by design; and the useful life of components and structures is nearly always limited by the materials properties. The essence of materials science and engineering is the study and exploitation of the interrelationships between synthesis, processing, composition, structure, properties, and performance of materials.
\end{abstract}

\section{Mission, Policy and National Trends}

The Materials Science and Engineering Laboratory (MSEL) is the Federal Government's central resource for measurement-related materials research in support of industrial needs. The Laboratory's program is directed toward facilitating the development and application of science and technology in U.S. industry by developing the scientific bases and critically needed measurement methods, calibration standards and reference data required for processing and using new advanced materials as well as existing materials more reliably and at lower cost.

The Laboratory plans it's programs in response to the basic NIST Organic Act, Administrative and Congressional policies and with an understanding and close tie to national trends in industrial and manufacturing technologies. During the past decade, a concurrent change in Administration policy and Congressional focus on enhanced industrial competitiveness in the international arena has led NIST to expand its traditional role. New programs have been enacted by Congress which will aid U. S. industries in developing new products or in improving current product quality, performance and cost, thus improving competitiveness within the international community. A major emphasis in the Laboratory's planning process has been to utilize close cooperation with industry to obtain input on national trends in materials research, measurement methods, data, and standards necessary to support manufacturing technologies. With this planning information, the Laboratory identifies gaps in current materials science research, data, and standards and develops plans whereby the Laboratory can make the broadest impact on major industrial sectors of the U. S. economy. 
Three major trends in the materials science community are fundamentally changing the process of transferring research output in materials science to industrially utilized materials. The first trend is the shift in balance from the traditional commodity materials to new, high technology, high value added materials which are developed specifically to satisfy one or more unique functional or structural needs. The technological and economic goals of many other countries also are tied to advances in materials, setting the stage for intense international competition. Industries which can rapidly and successfully adopt new materials into their manufacturing processes to improve performance, reliability, or cost will be in a position to develop a worldwide edge in competitiveness. A major factor in the MSEL response is the Laboratory's traditional role in characterizing and developing test methods, data, and standards for evaluating materials being developed by the $U$. $S$. materials science research community and aiding industry in using that information to improve materials performance in U. S. manufactured products.

The second trend reflects the evolutionary shift in industrial R\&D leadership away from primary materials producers to materials utilization industries. For metals, especially for aerospace and transportation applications, the users or fabricators of modern, highly specialized alloys are increasingly responsible for specifying alloy performance requirements and alloy development. The highly disaggregated producers of advanced ceramics cannot support the integrated research effort needed to commercialize advanced materials. In the composites community, the fabrication or lay-up of high performance composites is often carried out on-site by the component user. This change in R\&D focus in materials has led MSEL to develop increasingly closer ties with the materials users and has highlighted the need for MSEL to carefully select industrial partners in order to leverage NIST resources.

The final trend in materials science, recognizing the rapid development of new high technology materials, is the increased reliance industry will have on materials processing with remote sensing of materials characteristics to provide real time feedback to insure product quality and to improve cost competitiveness with both conventional and newer high technology materials. Research in materials processing will depend greatly on developing reliable data and process models to bring insight into the relationship between the physical and chemical properties of the material during processing and the functional or structural properties of the specific end-product material. This shift to real time materials characterization during processing will necessitate a strong and integrated Laboratory program in measurement research, materials data, modeling, nondestructive materials sensing, and the use of real time materials evaluation data in processing.

\section{Focus on Customers}

The MSEL industrial customer base is broad and includes primary materials, aerospace, ground vehicle, electronics and communications industries. Taking advantage of NIST's traditional role as facilitator or focal point for bringing together divergent or competing industries and companies, MSEL 
successfully serves as the interface between materials producers, such as the steel companies, and materials users, such as the automotive manufacturers. In response to the shift in materials R\&D leadership to utilization/manufacturing industries, the Laboratory has significantly increased its linkages to these larger, technology-driven companies within critical industrial sectors. Working through these companies, MSEL has also been able to interact with and have a greater impact on the difficult to reach small business community through the vendors/suppliers to the high technology firms. The Laboratory continuously monitors and evaluates the impact and value of its programs on the industry segments with which it is currently collaborating, and as financial and staffing resources permit, enhances these activities or re-directs programs into collaborations with new partners.

\section{MSEL Plan - Near Term}

The Laboratory has recognized and participated in the worldwide shift in materials research to complement incremental improvements in basic commodity materials by research into new and advanced materials designed specifically to satisfy functional or structural needs. To continue its leadership role in materials science research and its ability to respond to national priorities and needs, MSEL has developed a plan to: (1) extend traditional strengths in structural materials to encompass advanced materials; (2) expand programs in materials processing including sensor development and process modeling; (3) broaden materials coverage including those utilized for their electronic, optical, and magnetic properties; and (4) increase interactions with industry in areas of high mutual priority by the mechanism of joint technology development. Near-term efforts have focused on: Advanced Materials; Materials Manufacturing; Functional Materials; and Materials Characterization.

\section{ADVANCED MATERIALS}

One of the principal goals established by NIST and the Department of Commerce is to promote the rapid and competitive introduction by $U$. S. firms of products based upon emerging technologies. Advanced materials has been identified in a number of studies, including the 1989 DOD Critical Technologies Plan and by a recent department-wide study of Emerging Technologies, as prominent among these technologies. Unquestionably, there is a shift in the balance of materials usage to the manufacturing of hightechnology, high-value-added materials such as composites and advanced ceramics.

\section{Advanced Ceramics}

Advanced ceramics are a new generation of high-performance materials which have begun to provide the basis for high technology applications in both new and established industries. The special properties attainable in advanced ceramics (such as high dielectric strength, and resistance to high temperature, corrosion, and wear) make them the preferred, or only materials suitable for a broad range of high-performance uses in electronics, optics, 
structures, and advanced engine power trains. The major technical barrier impeding competitive commercialization of advanced ceramics is the inability to produce components reliably. This lack of reliability stems from the sensitivity of ceramic performance to small microstructural defects ( 1 nanometer to 100 micrometers) introduced during processing. The MSEL program addresses these technical issues through a measurement-based program designed to understand, predict, and control the origin and fate of these performance-limiting features, and to establish those critical linkages between processing variables, microstructures, material properties and performance that will markedly improve ceramic reliability.

\section{High-Performance Composites}

Composites are attractive substitutes for traditional engineering materials because of their high specific strength and stiffness, corrosion resistance, design and manufacturing flexibility, and effectiveness in conserving critical raw materials. Key technical barriers that limit full exploitation of composite materials are the high cost of fabrication and lack of understanding and predictive capabilities for performance. The present polymer matrix program addresses processing since advances in processing science and implementation of on-line process control are the keys to more rapid and reliable processing/fabrication. Efforts are focused on development of a composites fabrication facility, continued development of advanced sensors for process control, and research on resin transfer molding, identified by an industry workshop as a future key fabrication method. A significant industrial collaboration has been initiated with the Automobile Composites Consortium (Ford, General Motors, Chrysler) in which MSEL is developing critical resin flow models to describe the filling of molds containing composite preforms. Program expansion will be in the study of properties and performance. The emphasis will be on establishing the processing-structureproperty relationships that are needed to improve the ability to understand failure mechanisms and predict performance.

\section{MATERIALS MANUFACTURING}

Advanced manufacturing techniques increasingly demand materials of greater reliability and uniformity -- i.e., higher quality. Specific demands for properties and performance can be met by control of the processing of the desired material from synthesis to forming to joining stages.

\section{Intelligent Processing of Materials}

Process control requires four elements: a process model which relates specific materials properties at each stage of the process to the final realized properties; sensors which can measure the appropriate materials properties during processing; materials property data which must be coupled with the limited real time measurements in the process model; and rapid computational capability to enable incorporation of sensor data, process model evaluation, and process variable control -- all in real time -- to ensure 
optimum process control, or true intelligent processing of materials. The MSEL plan is to develop generic programs which integrate robust in-process materials property sensors with process models to achieve a high level of material control. Multidisciplinary teams of investigators from appropriate parts of MSEL and throughout NIST will be assembled, with close cooperation from industry materials producers from planning through program implementation, and coordinated with related programs at other Federal agencies. Working with the American Iron and Steel Institute (AISI) and the Department of Energy (DOE) as a follow-up to the 1989 NIST/DOE/AISI workshop on intelligent processing, MSEL is joining with the U.S. steel industry in developing a national, generic research agenda on intelligent processing of steel.

\section{Electronic Packaqing}

The loss of U. S. leadership in the electronics industry results from the inability to manufacture advanced electronic components of high quality at low cost. This leadership loss also affects the competitiveness of $U$. S. industry in rapidly advancing technologies such as telecommunications. Fabricating complex, advanced microcircuits on a commercial scale requires significant improvement in current manufacturing processes in part because of critical problems in connecting or packaging these devices with other parts of the component. As design trends demand smaller, thinner, and more complex packaging systems, problems of thermal load management and material properties that change with scale from bulk values to values for thin films become limiting. This challenge of electronic packaging and interconnections affects the reliability of the resulting product. MSEL has outlined a multiple approach which builds on budget initiatives and potential industrial collaboration through organizations such as the Semiconductor Research Corporation, and Microelectronics Center of North Carolina. The MSEL role is to develop the measurement tools necessary to define the critical properties (electronic, mechanical, thermal) of realistic packaging materials, including thin films and wires.

\section{FUNCTIONAL MATERIALS}

The term "functional materials" denotes classes of materials which are used in various technological applications because of their specific functional purposes -- for example, electrical, magnetic, or optical functions. These materials play an enabling role in some of the key techno-economic areas such as the electronics industry, telecommunications, and in contemporary information technology.

\section{Superconductors}

This new technology ultimately will have an impact on many fields traditionally supported by the Laboratory. high temperature superconductor technology, technical problems, including difficulty of The development of a practical however, is limited by a number of fabricating components and the 
inability of these materials to carry the necessary large electric currents. A NIST-wide coordinated program supports this embryonic industry with the development of basic technology in a number of areas, including composition and structure analysis, measurement methods for magnetic characterization, and data for design and control of fabrication processes. Using the unique combination of facilities and expertise, the MSEL program component will build on its strength in phase diagrams, $x$-ray and neutron crystallography, magnetic characterization, and mechanical property measurements.

\section{Maqnetic Materials}

Magnetic information storage technology has been targeted by Japan as a key industry in the struggle for world market dominance in information technology and supercomputers. Over the last decade, major advances have been made in magnetic materials not only for magnetic recording but for applications in advanced electronic systems and the transmission and distribution of electric power. U. S. industry has difficulty in competing because many companies cannot support a sufficiently large research and development effort to keep pace in this rapidly changing technology. The MSEL plan contained in a FY 92 initiative request is to utilize a broad-measurement based program to combine structural information from neutron scattering measurements in the NIST reactor, magnetic properties coupled with structural defect analysis and tribological measurement technology development applied to new magnetic materials.

\section{Photonic or Magneto-Optic Materials}

The promise of optical technology to bring dramatic improvements in telecommunications, information processing and storage is the major driving force for commercialization of photonic technology. In this technology of the future based on using thin films and multilayers, the required properties and performance of these materials are strongly affected by defects and their distribution within the material. New techniques are required for processing, characterization, and control. Limited internal re-direction of resources has led to modest pilot efforts in magneto-optics from nanocomposite materials, optical thin films from metal oxide chemical vapor deposition (MOCVD), and optical thin films based on polymer liquid crystals. Characterization efforts are being reorganized to couple x-ray techniques, neutron reflectometry, and chemical characterization into a multi-technique program.

\section{MATERIALS CHARACTERIZATION}

MSEL has an integrated program in microstructural characterization utilizing a complete array of techniques and associated instrumentation for the spatially resolved measurement of materials. MSEL facilities include optical and electron microscopy; optical, x-ray, electron scattering and diffraction, including a major facility at the National Light Source at Brookhaven Laboratory; and an array of nuclear beam techniques utilizing the NIST Research Reactor, including the Cold Neutron Research Facility as a national user facility. 
A multi-year program for the development of an internationally competitive cold neutron research capability (facility) has been initiated to provide $U$. S. scientific and industrial communities with the most advanced facility for measurement of materials at both atomic and macromolecular levels using neutron techniques. This measurement facility, coupled with other state-ofthe-art measurement capabilities within the Laboratory provide scientists with world class measurement capabilities with which to study the composition/structure/property relationships of newly developed materials. These advanced measurement technologies have broad application in basic and applied science directly relevant to the materials, information and communication, transportation, chemical, electronics, and biotechnology industries. Access to a cold neutron research facility is an important step toward allowing $U$. S. materials based industries to compete successfully with other industrialized nations in the development of new and improved materials and products. Fifteen state-of-the-art research stations are in planning, design, or under construction. Strong industrial financial and scientific support has been obtained for the development and operation of several of these instrument systems.

MSEL Plan - Longer Term

Although the rapid pace of technological change in materials technologies continues, new, interdisciplinary topics with high impact potential have been identified as future areas of MSEL focus. Significant industrial measurement needs are anticipated in some of these areas, while others offer exciting new science opportunities. These topics include: surfaces/interfaces/coatings; nanostructural materials; and modelling/theory. Currently, limited exploratory programs are underway in MSEL in these targets of opportunity but the efforts lack critical mass and are not capable yet of responding to significant extramural demands.

Surfaces/interfaces/coatings represent typically two dimensional systems and offer the challenge of combining neutron scattering strengths with other nondestructive evaluation techniques in studying metal, ceramic, polymer, and composite materials. Nanostructural materials or nanocomposites represent material classes where important properties are controlled by the small scale of the material features. Finally, the rapidly changing materials scene can greatly benefit from fresh approaches to condensed matter theory and modeling of the solid state that are now feasible because of the ready availability of high speed computers and computation methods. 
The materials industry today is in the midst of a technological explosion that is creating major economic opportunities for those nations willing to commit scientific and engineering resources to capture them. With these opportunities being driven by market demand and scientific understanding, a whole host of industries are designing sophisticated and efficient products to be made from materials that today still are in the laboratory. NIST can play a major role in assisting U. S. industry to develop some of the capabilities needed for the commercialization of many of these materials. The rapid advancement in understanding the fundamental relationship between materials and their structures in the last 15 years now can be applied to the development of a new body of knowledge critical to the design, characterization, testing and, in particular, the processing and manufacturing of a new generation of advanced materials. 


\section{Selected Highlights}

A patent was issued to the U.S. Government for a composite material made by dispersing a powdered high $T_{c}$ superconductor in a low $T_{c}$ polymer. The composite has the processing advantages of a polymer and the levitation properties of a superconductor at temperatures below $T_{c}$.

The first direct evidence for the effect of twin boundaries on flux pinning in YBaCuO has been observed by researchers in the Ceramics Division. These measurements show that twin boundaries are not effective flux pinning sites and, therefore, grain boundaries may not necessarily restrict the performance of these materials.

The Metallurgy Division's SiGMA system (Supersonic inert Gas Metal Atomization) has been used to produce fine spherical metal powder $(50 \%$ by weight $\leq 20 \mu \mathrm{m}$ ) of materials that are difficult or impossible to produce by ingot techniques. New types of materials produced included nitrogenated steels and $\mathrm{Cu}-\mathrm{Sn}$ intermetallic compounds that occur in solder joints.

This year, a three-year NIST/U.S. industry consortium project on the atomization of metal powder was completed with an impressive list of accomplishments, including a fundamental understanding of the liquid jet breakup leading to a process model of droplet formation; real-time techniques for measuring droplet size and its distribution; and an expert system for control of the atomization process based in part on the process model.

During manufacture, the determination of internal temperature distribution of aluminum has been a troublesome problem for the aluminum industry. In a joint effort between MSEL and The Aluminum Association, theoretical and experimental results showed that a multifrequency eddy current measurement approach provided an NDE temperature sensor for process control of moving sheet and plate.

Field trials were conducted in two prototype ultrasonic NDE instruments. A formability sensor system was delivered to the Ford Motor Company for evaluation at the Dearborn stamping plant. An ultrasonic system for roll-by inspection of railroad wheels is being evaluated at the American Association of Railroads test track in Pueblo, Colorado.

A high resolution ultrasonic system has been developed in the Materials Reliability Division for inspecting thick polymer-matrix composites.

The high dynamic range (60dB) and large band width $(60 \mathrm{kHz}$ to $60 \mathrm{MHz}$ ) of the new system permits characterization of material property variations and detection of flaws.

Initial results confirmed the feasibility of utilizing on-line eddy current conductivity sensors to monitor the high temperature baking and pyrolyzes of carbon-carbon composites. The data produced will result in improved quality and higher process yield. 
A previously developed thermodynamic model and its accompanying database was expanded. The model is applicable to iron-making slags and many refractories for the prediction of detailed composition and phase properties of multicomponent-multiphase iron and advanced refractorycontaining oxide systems.

Polymer Division scientists have developed a new model to describe the flow in resin transfer molding (RTM). By considering the heterogeneous nature of the fiber perform, the model is able to predict a number of previously unexplained features that had been observed in RTM experiments.

Computer programs have been developed to convert coordinate points on solder joint surfaces obtained by $x$-ray laminography and optical inspection into finite element meshes for stress analysis. Automated stress analysis will permit rapid assessment of the significance of geometric irregularities on the reliability of solder joints in electronic packages.

Reactor Radiation Division scientists have developed a magnetoelastic formalism for rare earth artificial metallic superlattices which predicts the dependence on epitaxial strain of the ferromagnetic to helical phase transition temperature and, equivalently, the magnitude of applied field required to artificially induce this transition. This theoretical result has recently been confirmed in experiments on new superlattices or dysprosium interleaved with non-magnetic lutetium.

Biological macromolecules have been used to produce an electron density map of the known structure of native bovine chymosin that is in remarkable agreement with the conventionally refined structure from a heavy-atom substituted specimen. This achievement opens the way to a major advance in the ability to determine the phases, ab initio, from native protein data.

The 10-meter SAxS facility in the Polymers Division had active outside users from 7 industrial laboratories, 2 academic institutions, and 3 other federal laboratories. Activities of users include: structure/property/processing relationships in blown polyethylene films, microstructure in polypropylene, polyester and nylon fibers, morphology of amorphous/semicrystalline nylon blends and properties of carbon aerogels.

Densification of nanosize (10-40 nm) silicon nitride powders at high pressures and low temperatures has been obtained without the addition of sintering aids. The resulting ceramics are transparent and show high fracture toughness. 
The physical and mechanical properties of the intermetallic compounds that form in lead-tin solder connections to copper were measured, most of them for the first time. These measurements revealed, among other things, that these compounds are harder than high-strength steel at room temperature but only twice as tough as glass.

The Reactor Radiation Division in cooperation with optoline Associates, Ovonics Co. and Oak Ridge National Laboratory have made a major breakthrough in a joint program of research and development of the neutron optical devices known as supermirrors. These vapor-deposited, layered structures transport neutron beams from the reactor (or other) source to experimental stations with significantly increased intensity relative to conventional guides. These results will play a major role in re-establishing the U.S. as the leader in materials research with neutrons.

The Structural Ceramics Database, Version 1.0, has been prepared and is now offered for sale by the office of Standard Reference Data. This user-friendly computerized system contains evaluated thermomechanical property data suitable for materials selection by designers of industrial equipment. 


\section{RESPONSE TO 1989 PANEL CONCERNS}



This section details specific concerns raised by the MSEL Panel on Assessment in their 1989 Evaluative Report and presents MSEL management actions taken in response to those concerns. A more complete discussion of these concerns will be held during the 1990-1991 Panel meeting.

CONCERN: "The Panel is concerned with the gradual increase in the percentage of funding coming from outside sources. The panel believes that such outside funding should not exceed the 30 to $40 \%$ level."

RESPONSE: This concern has been raised by past panels in various forms. Although it continues to be a concern of MSEL management, this year we are more optimistic that the Laboratory can achieve the $60 \%$ base funding level recommended by this and past Panels. In $F Y$ 1991, MSEL received an increase in appropriated funding of $\$ 900,000$ for beginning the program in Intelligent Processing of Materials, $\$ 550,000$ for the second phase of the Polymer Composites program, and $\$ 100,000$ to complete the MSEL program in High Temperature Superconductivity. Additionally, the Laboratory is optimistic about new resources in the 1992 and 1993 budget process. Details of the MSEL Strategic Plan are given in the Overview section of this Report.

CONCERN: "The Panel is concerned with the large number of foreign guest scientists in relation to the new role of NIST --- in U. S. industrial competitiveness on the world markets."

RESPONSE: The MSEL management does not find this concern compelling. The NIST guest scientist program, including the foreign guest scientists, add measurably to the technical competence of our permanent staff. All guest scientists are invited individually by a NIST staff member and reviewed and approved by the Laboratory Director. In programmatic areas of sensitivity, guest researchers are excluded from information exchange. We believe the benefits from the guest scientist program to NIST and MSEL programs far outweigh any potential risk from loss of sensitive information.

CONCERN: "The Reactor Radiation Division must be given the financial support to be able to run the users program --- while at the same time permitting the staff scientists to carry out RRD's own research program."

RESPONSE: Dr. Michael Rowe, Chief of the Reactor Radiation Division, is aware of this concern and has initiated a hiring plan to insure a full range of user services to collaborators who plan to use the new national facility for cold neutron research. He has hired one senior staff member already to assist him in all areas related to the national facility. MSEL has a request in the 1993 NIST budget submission for additional resources to assist in the operation of 
the CNRF as a national facility. NIST management has been extremely supportive of the RRD's efforts to develop the best facility for neutron research in the U. S.

CONCERN: "The Panel is concerned that MSEL and NIST do not have a clear intellectual property rights position. The panel recommends that a concerted effort be initiated to develop a strategy."

RESPONSE: During the past year, the NIST Director appointed Lyle Schwartz to chair a committee composed of the NIST legal council and the Deputy Directors of each of the new Laboratories. The charge of the committee was to review current NIST policies on intellectual property and make recommendations to the NIST Director on areas needing revisions. The committee met regularly for about four months, reviewed intellectual property implications of our new legislation, current NIST policies, policies of other federal agencies and developed a series of recommendations for the Director. The recommendations have been accepted by the Director and changes in the NIST administration manual are in process.

CONCERN: "The Panel suggested that an evaluation of the role of the office of Nondestructive Evaluation (ONDE) be conducted and consideration be given to broadening it's role --- to assist in coordination of major efforts involving interdivision or interdisciplinary programs."

RESPONSE: MSEL management agrees with this recommendation. ONDE has been assigned the management coordination responsibility of the new program on Intelligent Processing of Materials as well as it's traditional programs on development of sensors for NDE. In this role, ONDE will review proposals from throughout NIST on Intelligent Processing of Materials (IPM) research programs and make recommendations to the Director, MSEL on projects for funding. The office will use MSEL initiative funds for interdivision MSEL projects and will coordinate with other NIST Laboratories to facilitate inter-laboratory programs. 
PERSONNEL 



\section{Full Time Permanent}

Physicist

Chemist

Metallurgist/Matls. Scientist

Engineer

Other

Technical Support

Reactor Operators

Management Support

Secretarial/Admin. Support Subtotal

TOTAL FTP

$\begin{array}{ccc}1988 & & 1989 \\ 66 & 61 & \frac{1990}{49} \\ 46 & 43 & 52 \\ 47 & 54 & 48 \\ 42 & 41 & 35 \\ \frac{9}{210} & \frac{12}{211} & \frac{12}{206}\end{array}$

$\begin{array}{ccc}32 & 32 & 38 \\ 15 & 16 & 17 \\ 12 & 11 & 8 \\ \frac{28}{87} & \frac{31}{90} & \frac{35}{98} \\ 297 & 301 & 304\end{array}$

Other

NRC-NAS Postdoctorals

15

9

14

Part-Time and Temporary

29

27

20

Academic (Student and Faculty)

Subtotal

$\frac{51}{95}$

$\frac{42}{79}$

$\frac{49}{83}$

TOTAL STAFF 


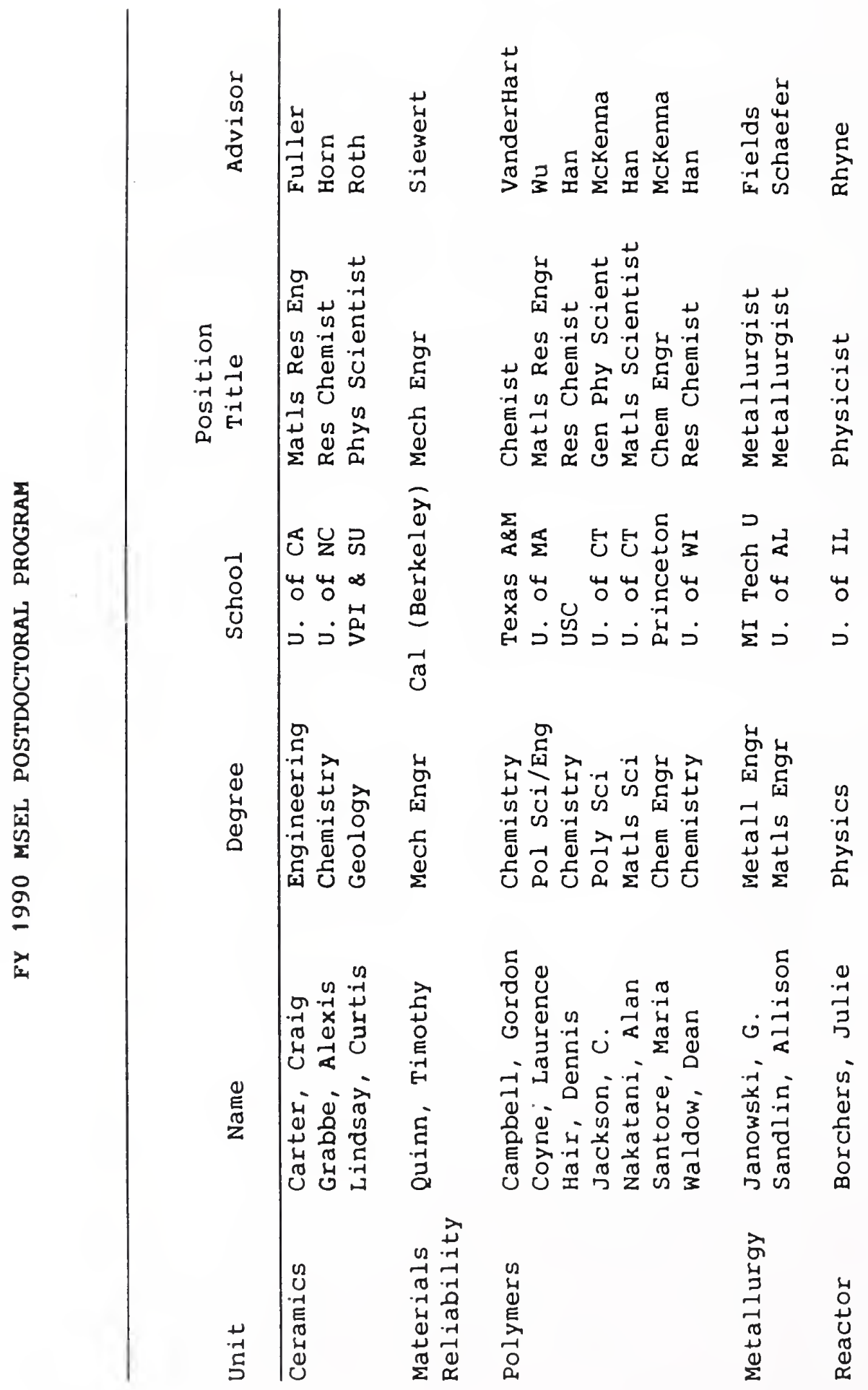


FY 1990 MSEL ACADEMIC PROGRAM

\begin{tabular}{|c|c|c|c|c|}
\hline \multicolumn{5}{|c|}{ Appointments } \\
\hline & $\begin{array}{l}\text { rgraduate } \\
\text { udents }\end{array}$ & $\begin{array}{l}\text { Graduate } \\
\text { Students }\end{array}$ & Faculty & Totals \\
\hline Directors office & --- & 1 & --- & 1 \\
\hline Ceramics & 7 & 5 & --- & 12 \\
\hline Materials Reliability & 12 & 3 & 2 & 17 \\
\hline Polymers & 2 & 1 & 3 & 6 \\
\hline Metallurgy & 8 & -- & 3 & 11 \\
\hline \multirow[t]{2}{*}{ Reactor Radiation } & 1 & $\underline{---}$ & 1 & $\underline{2}$ \\
\hline & 30 & 10 & 9 & 49 \\
\hline
\end{tabular}


MSEL VISITING SCIENTIST PROGRAM

Guest Researchers

FY 1988

FY 1989

FY 1990

Domestic

Federal

Academic

52

104

54

57

Industry

28

79

82

Self-Employed

$\frac{23}{207}$

29

48

Subtotal

$\frac{20}{182}$

$\frac{19}{206}$

Foreign

Subtotal

$\frac{74}{281}$

$\frac{136}{318}$

$\frac{174}{380}$

Research Associates

Federal 5

Academic

17

3

6

Industry

68

82

0

47

Research Agreements

$$
\begin{aligned}
& \text { Federal } \\
& \text { Academic } \\
& \text { Industry } \\
& \quad \text { Subtotal }
\end{aligned}
$$

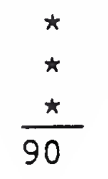

1

362
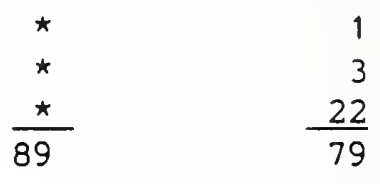

Intergovernmental Personnel

Act (Academic)

TOTAL

^Not available as separate line item 


\begin{abstract}
GOLD MEDAL (Exceptional Service)
George Birnbaum

for highly distinguished authorship and editorship in molecular spectroscopy and for his unusually outstanding scientific leadership in the NDE program. (1989)

Arnold H. Kahn

for theoretical studies of electromagnetic field interactions with metals and alloys. (1988)
\end{abstract}

\title{
SILVER MEDAL (Meritorious Service)
}

\section{Alan Dragoo Stephen Hsu Subhasch Malghan}

Roger Horn

Douglas Smith

Donald Hunston

Ivan Schroder

E. Neville Pugh and Ugo Bertocci

Reactor Operations Group for leadership of the International

Round Robin on Ceramic Powder Characterization to advance standards for characterization of advanced ceramic powders. (1990)

for development of surface force measurement technology using chemically reactive surfaces (silica). (1990)

for outstanding scientific and managerial leadership in the investigation of adhesion and the processing and performance of polymer composites. (1990)

for outstanding contributions to the Department and nation through his innovative design and development of the neutron guide tube network at the cold Neutron Research Facility (CNRF). (1990)

for significant advances in the understanding of environment induced cracking of engineering metals and alloys. (1989)

for excellence in all aspects of the operation of the NIST Reactor. (1989) 
Joseph J. Ritter

Antonio Santoro

Haydn N.G. Wadley for pioneering research which led to novel routes for producing ceramic powders.

(1988)

for developing highly important theoretical and experimental methods for measurement of the structures of materials. (1988)

for contributions to a program aimed at the development of sensors and their integration into automated control systems for materials processing. (1988)

\section{BRONZE MEDAL (Superior Service)}

Robert Briber

James Gottas

Debra Kaiser

Frank Gayle

Stephen Norton

Raymond Schramm

Barry J. Bauer for significant contributions in the area of complex phase behavior of polymer blends, including determination of the phase diagram and dynamics of crystallization. (1990)

for outstanding contributions to the cold Neutron Research Facility through his energy, dedication, and creativity in the development of a Cold Neutron Source at the NIST Reactor. (1990)

for development of a thermomechanical technique to produce twin free single crystals of superconducting, yttrium, barium copper oxide. (1990)

for innovative contributions to the use of nondestructive evaluation sensors for materials process control, including development of mathematical approaches that allow sensor data to be converted to useful process information. (1990)

for development of a railroad wheel inspection system based on electromagnetic acoustic transducers, including the signal analysis software, and the associated digital electronics. (1990)

for outstanding contributions to the synthesis and characterization of crosslinked interpenetrating polymer networks. (1989) 
Douglas Blackburn

Carol A. Handwerker

Robert H. Williams

John E. Blendell

Yi-Wen Cheng

Edmund A. Di Marzio

Paul A. Ropetka

Stephen D. Ridder

Gery R. Stafford for development of glasses or glass standards in support of the optical, analytical chemical, and glass industries. (1989)

for providing new understanding of interface reactions and processes that cause roughening at interfaces in composite materials. (1989)

for outstanding contributions to the development and operation of the research facilities at the NIST Reactor, and for leadership in the planning and installation of instrumentation at the Cold Neutron Research Facility. (1989)

for outstanding contributions and leadership in the development of processing high-temperature ceramic superconductors. (1988)

for development of a thermomechanical processing simulator. (1988)

for outstanding theoretical contributions to the understanding of glass transition, polymer crystallization, non-exponential relaxation in amorphous materials, polymer interfaces, and structure induced phase transition. (1988)

for engineering design, supervision of fabrication, and the final testing and installation of the NIST cold neutron source. (1988)

for outstanding contributions to the study of atomization processes in metals. (1988)

for contributions to the understanding of the electrochemical deposition of aluminum-titanium intermetallic compounds. (1988) 


\section{SPECIAL ACTS}

Edward Begley

Subhas Malghan

Deborah Northup for contributions to the development of a computerized structural ceramics database. (1989)

for leadership in formulating an industrially relevant program of research in fine ceramic powder processing. (1989)

for extraordinary facility in quickly assuming increased duties as secretary of a much larger group and efficiently carrying out the duties under unusual supervisory circumstances. (1989)

FELLOW AND SENIOR FELLOW (Established by NIST Director to provide recognition to most outstanding scientists)

John Cahn

Brian R. Lawn

John J. Rush

Robb M. Thomson

Sheldon M. Wiederhorn
Elected to Senior Fellow

Elected to Fellow

Elected to Fellow

Elected to Fellow

Elected to Senior Fellow 


\section{NIST AWARDS}

$\underline{1988-1990}$

EDWARD UGLER CONDON (Distinguished achievement in written exposition in science and technology)

Gregory B. McKenna

for his excellent review of the properties and physics of polymer glasses. (1989)

EDWARD BENNETT ROSA (Outstanding achievements in the development of significant standards of practice in the measurement field)

Leonard Mordfin

for outstanding leadership in the standardization of mechanical testing and nondestructive evaluation (NDE) methods and measurements. (1989)

Samuel J. Schneider

for outstanding contributions and leadership activities in developing and promoting standards in materials science and engineering. (1988)

SAMUEL WESLEY STRATTON (Outstanding scientific or engineering achievements in support of NIST objectives)

Charles Han

for his leadership in advancing the science and technology of polymer blends through use of innovative light scattering and neutron scattering techniques to produce benchmark data. (1990)

EUGENE CASSON CRITTENDEN (Outstanding supporting services)

Dale Rauffman

for significant contributions to the synthesis of glass standards of unusual compositions which have supported the optics, medical, and analytical chemistry fields. (1990)

\section{SAFETY (Significant contributions to Safety Program)}

Patricia Salpino

John E. MCRinney for exceptional and effective efforts in fulfilling duties as the safety officer of the office of Nondestructive Evaluation. (1989)

for leadership of the safety program in the Polymers Division. (1988) 
EXTERNAL RECOGNITION

$\underline{1988-1990}$

George Birnbaum

George Birnbaum

George Birnbaum

Aime DeReggi

John Gudas

Howard P. Layer

Gregory B. McKenna

Marshall Peterson

Arthur W. Ruff
A.C. Sandlin
R.J. Schaefer
L.C. Smith

Leonard C. Smith

Debra L. Raiser

Prank . Gayle

Lyle H. Schwartz
Visiting Fellow - Johns Hopkins University (1990)

Appointed Associate Editor of the Research in Nondestructive Evaluation Journal of ASNT (1990)

Appointed Associate Editor of Journal of Quantitative Spectroscopy and Radiative Transfer (1990)

Invited Professor at Ecole Superieure de Physique et de Chimie Industrielles, Paris, France, (1989); (1990)

ASTM Award of Merit for distinguished leadership and exceptional contributions in the promotion and development of elastic plastic test standards. (1990)

Elected Fellow of the American Physical Society (1990)

Vice Chairman, Division of High Polymer Physics of the American Physical Society (1990)

Society of Tribologists and Lubrication Engineers - National Award for Significant Scientific Contributions to the Fields of Tribology (1990)

Honorary Fellow of ASTM for Dedicated Service (1990)

Fourth place award for photograph. Polaroid International Photomicroscopy Competition (1990)

First place award in the Crystal Growth Photograph Competition at Eighth American Conference on Crystal Growth (1990)

Presidential Rank Award of Meritorius Executive for outstanding government service (1990) 


\begin{tabular}{|c|c|}
\hline H. Thomas Yolken & $\begin{array}{l}\text { Appointed by President of the American Society } \\
\text { for Nondestructive Evaluation to Committee to } \\
\text { establish a major new organizational unit for } \\
\text { the Society - The Research Council (1990) }\end{array}$ \\
\hline L.H. Bennett & Sigma Xi Award (1989) \\
\hline George Birnbaum & $\begin{array}{l}\text { Appointed research professor in the Physics } \\
\text { Department of the Catholic University of America } \\
(1989)\end{array}$ \\
\hline william Boettinger & $\begin{array}{l}\text { Materials Science Division Award of ASM } \\
\text { International (1989) }\end{array}$ \\
\hline Frederick Brinckman & $\begin{array}{l}\text { Harold A. Iddles Lecturer of the Department of } \\
\text { Chemistry, University of New Hampshire (1989) }\end{array}$ \\
\hline Edmund DiMarzio & $\begin{array}{l}\text { Huggins Award - given by Gordon Conference for } \\
\text { outstanding work in Polymer Science (1989) }\end{array}$ \\
\hline David S. Lashmore & $\begin{array}{l}\text { International Electrodeposition Award, } \\
\text { Electrochemical Society (1989) }\end{array}$ \\
\hline Leonard Mordfin & $\begin{array}{l}\text { ASTM Award of Merit and the title of Fellow of } \\
\text { the Society for distinguished leadership and } \\
\text { exceptional contributions in the promotion, } \\
\text { development, and growth of the ASTM Committee on } \\
\text { Mechanical Testing (1989) }\end{array}$ \\
\hline Gregory B. McKenna & $\begin{array}{l}\text { Elected Fellow of the American Physical Society } \\
(1989)\end{array}$ \\
\hline $\begin{array}{l}\text { H.J. Prask and } \\
\text { C.S. Choi (Guest) }\end{array}$ & $\begin{array}{l}\text { Department of Army Research and Development } \\
\text { Achievement Award; for developing and applying } \\
\text { neutron diffraction to the determination of } \\
\text { subsurface residual stress in a variety of } \\
\text { military hardware (1989) }\end{array}$ \\
\hline Richard P. Reed & $\begin{array}{l}\text { Outstanding Scientist/Engineer Award from the } \\
\text { Denver Federal Executive Board as part of its } \\
\text { annual Excellence in Government Awards Program } \\
(1989)\end{array}$ \\
\hline Harry Rook & $\begin{array}{l}\text { Elected Chairman of ASTM Committee D-22 Sampling } \\
\text { and Analysis of Atmospheres (1989) }\end{array}$ \\
\hline Harry Rook & $\begin{array}{l}\text { Elected permanent Chairman of ISO TC } 146 \\
\text { Subcommittee } 3 \text { - Committee on Standards for } \\
\text { Atmospheres (1989) }\end{array}$ \\
\hline
\end{tabular}

Appointed by President of the American Society for Nondestructive Evaluation to Committee to establish a major new organizational unit for the Society - The Research Council (1990)

Appointed research professor in the Physics Department of the Catholic University of America (1989)

Materials Science Division Award of ASM

Harold A. Iddles Lecturer of the Department of Huggins Award - given by Gordon Conference for outstanding work in Polymer Science (1989)

International Electrodeposition Award, ASTM Award of Merit and the title of Fellow of the Society for distinguished leadership and exceptional contributions in the promotion, development, and growth of the ASTM Committee on Mechanical Testing (1989)

Elected Fellow of the American Physical Society $(1989)$

Department of Army Research and Development Achievement Award; for developing and applying subsurface residual stress in a variety of military hardware (1989)

Outstanding Scientist/Engineer Award from the Denver Federal Executive Board as part of its annual Excellence in Government Awards Program

Elected Chairman of ASTM Committee D-22 Sampling and Analysis of Atmospheres (1989)

Elected permanent Chairman of ISO TC 146 Subcommittee 3 - Committee on Standards for Atmospheres (1989) 
Tom Siewert and Christopher McCowan

Thomas Siewert

H. Thomas Yolken

David S. Lashmore

Chris McCowan

Marshall Peterson

Dominique Shepherd

Thomas Siewert

Sheldon Wiederhorn
Recipients of the American Welding Society McKay-Helm Award, recognizing a substantial contribution in the field of welding, was presented for paper on ferrite phase prediction in stainless steel welds (1989)

Selected as the annual recipient of the American Welding Society Honorary Membership Award (1989)

Appointed editor-in-chief of The American Society for Nondestructive Evaluation's (ASNT) new journal, Research in Nondestructive Evaluation (1989)

Elected President of the Electrodeposition Division of the Electrochemical Society (1988)

Honorable Mention Award at the International Metallographic Contest, for his contribution, "Microstructural Characterization of $\mathrm{Y}-\mathrm{Ba}-\mathrm{Cu}-\mathrm{O}$ Superconductors" (1988)

The Mayo D. Hersey Award of the ASME, in recognition of his many contributions which led to an improved understanding of friction, wear, and lubrication of materials. (1988)

First Place Award at the International Metallographic Contest, for poster, "Advantages of Light Microscopy for Measuring Twin Dimensions in High-Temperature Superconductors" (1988)

Selected as the annual recipient of the American Welding Society Honorary Membership Award (1988)

Dow Distinguished Lecturer in Materials Science and Engineering, Northwestern University, Department of Materials Science and Engineering, in recognition of his outstanding contributions to materials science and engineering (1988) 
TECHNOLOGY TRANSFER 



\section{CONFERENCE PROGRAM \\ ( $S P O N S O R$ OR CO-SPONSOR) \\ FISCAL YEARS 19881989,1990}

NIST Testing Methodology for Glass, Glass-ceramic, and Ceramic Matrix Composites workshop

February 8, 1990 (D. Cranmer-Ceramics)

35 attendees

To review test methodologies and data requirements for composite property determination.

NIST/ASM Symposium on Intelligent Processing of Materials

March 1, 1990 (J. Carpenter-Ceramics)

30 attendees

To review the state-of-the-art intelligent processing.

Advances in Materials Science and Applications of High Temperature Superconductors

April 2-6, 1990 (L. Bennett-Metallurgy), NASA Goddard Space Flight Center 120 attendees

To review progress in development of high temperature superconductors.

Seminar on Relaxation in Condensed Materials

April 18, 1990 (J. Douglas-Polymers)

50 attendees

To bring together experts on theoretical and experimental aspects of relaxation in condensed materials.

Workshop on Measurements of Properties of Materials in Microelectronic Packaging

May 1-3, 1990 ( $\mathrm{J}$. Carpenter-Ceramics)

70 attendees

To determine a research agenda for measurements and properties of microelectronic packaging.

Interagency Coordinating Committee on Structural Ceramics

May 10-11, 1990 (S. Dapkunas-Ceramics)

30 attendees

To coordinate federal agencies research programs in structural ceramics research. 
Industry Workshop on Polymer Composite processing

May 18, 1990 (D. Hunston-Polymers)

26 attendees

To ascertain industry's view of the most important processing methods for the future.

NIST Surface Forces Workship

May 31-June 1, 1990 (R. Horn; D. Smith-Ceramics)

15 attendees

To exchange results from experimental programs on surface forces research.

Diamond Optics III at the 34 th Annual International Technical symposium on

Optical and Optoelectronic Applied Science and Engineering

July 8-10, 1990 (A. Feldman-Ceramics), San Diego, CA

120 attendees

To review diamond film research.

1990 ASTM Johnson Conference, Our Changing Atmosphere: Challenges in

Measurement Technology

July 8-13, 1990 (H. Rook-Laboratory office)

60 attendees

A comprehensive review of measurement science for the atmosphere and

discussions in the areas of environmental and atmospheric measurements.

American Ceramic Society/American Society of Nondestructive Testing Conference NDE of Modern Ceramics

July 9-12, 1990 (G. White-Ceramics), Columbis, OH

130 attendees

To review research on NDE of ceramics.

Eighth American Conference on Crystal Growth

July 15-20, 1990 (D. Kaiser-Ceramics), Vail, CO

350 attendees

To review research on crystal growth and analysis.

Gordon Research Conference

August 13-17, 1990 (J. Antonucci-Polymers), New Hampton, $\mathrm{NH}$

97 attendees

International meeting devoted to the "Science of Adhesion" while focusing on the fracture mechanical aspects of adhesion. 
NIST Mechanical Testing Methodology for Ceramic Design and Reliability

Workshop

September 5-7, 1990 (D. Cranmer-Ceramics)

50 attendees

To identify data and experimental methodologies required for ceramic design and reliability.

SE Reqional Meeting for Materials Science - Workshop on Regional Cooperation September $10-11,1990$ ( $R$. Thomson-Laboratory office)

30 attendees

To coordinate priorities in materials science for the SE. The results of this regional meeting will become input to a National Plan in Materials.

Computerization of Welding Information

September 12-14, 1990 (T. Siewert-Materials Reliability), Ypsilanti, MI 60 attendees

Recent advances in off-line planning systems, real-time welding information systems, data standards and case studies of computer applications for welding.

U.S. Assessment of the New Diamond Technology in Japan

September 13, 1990 (A. Feldman-Ceramics), Arlington, VA

50 attendees

To exchange information gained in assessments of Japanese diamond film technology.

NIST Workshop on Ceramic Machining

September 19, 1990 (S. Dapkunas-Ceramics)

35 attendees

To identify research needs in ceramic machining.

4 th U.S. /Japan Workshop on Low Temperature Structural Materials and Standards October 1-2, 1990 (H. MCHenry-Materials Reliability), Vail, CO

25 attendees

Recent research on alloys and composites to be used in $4-K$ superconducting magnets for fusion energy devices was reported at the workshop.

Conference on Development of Advanced Materials - Current Issues and Prospects December 17-19, 1990 (S. Wiederhorn-Laboratory office)

50 attendees

Polymers West Gordon Conference

January 1-6, 1989, (E. DiMarzio-Polymers), Ventura, CA

International meeting devoted to "Phase Transition in Polymers" with an emphasis on self-assembling systems. 
Workshop on Solidification and Microstructure Evaluation

February 2, 1989 (J. Simmons-Metallurgy)

15 attendees

Technical symposium on NDE methods to evaluate microstructure in metallic structures.

Nonconventional Ultrasonic Instrumentation and Methods in Nondestructive Evaluation of Composite Materials and Structures

February 15, 1989 (H.T. Yolken-ONDE)

20 attendees

In this seminar, three nonconventional techniques are described: air-coupling to materials that should not be immersed, high-power ultrasonics to inspect "thick" structures, and broadband signals to measure the frequency dependence of attenuation and velocity.

Engineering Foundation Conference on Structural Ceramics - Science and Technology

March 12-17, 1989 (S. Wiederhorn-Laboratory office)

54 attendees

The purpose of this conference was to assess the current state of the art/science in structural ceramics with a particular emphasis on automotive and truck applications. Areas for future research, both basic and applied, were identified.

\section{Materials Aspects of High-Temperature Superconductivity}

March 20-24, 1989 (E.R. Fuller, Jr.-Ceramics)

240 attendees

These were special focussed sessions organized for the Materials Physics Topical Group and the Division of Condensed Matter Physics as part of the 1989 March Meeting of the American Physical Society held in St. Louis, Missouri.

\section{Alternatives in Glass Research Symposium}

March 23, 1989 (M. Cellarosi-Ceramics)

15 attendees

This meeting focused on the critical research issues and alternatives in the glass industry. The meeting was co-sponsored with the Industry University Center for Glass Research at Alfred University (CGR), which comprises industrial interests planning to confront head on the problems facint their industry - competition from foreign manufacturer, competitive materials, and use of glass in high technology applications.

Sixth International Conference on High Temperatures

April 3-7, 1989 (J.W. Hastie-Metallurgy)

150 attendees

Technical symposium on high temperature chemical reactions 
Advanced Composite Materials Characterization and Test Methods: NIST-ASM

April 5-6, 1989 (R.E. Ricker-Metallurgy)

60 attendees

Short course on composite properties.

Description of NDE Research and Services Atomic Energy Research Establishment April 6, 1989 (H.T. Yolken-ONDE)

20 attendees

Air Force office of Scientific Research (AFOSR) Program Review

April 10-11, 1989 (D. Cranmer-Ceramics)

55 attendees

The purpose of this conference was to review the status and future plans of the current efforts of AFOSR contractors in the ceramics and non-metallics structural materials area. An assessment of future research program areas of interest to AFOSR was also made.

American Chemical Society Symposium on Tribology

April 10-11, 1989 (S.M. Hsu and J. Perez-CeramiCs)

50 attendees

The symposium covered several areas in tribology including the use of fractals, surface chemistry and lubrication mechanisms. It was held in the honor of Professor Elmer Klaus who has made significant contributions to lubrication in the past 45 years.

American Chemical Society - Special Symposium on Chemistry and Chemical Engineering in Tribology

April 12, 1989 (S.M. Hsu-Ceramics)

60 attendees

The objective of this symposium was to explore the current state-of-the-art in chemistry at interface.

Society of Tribologists and Lubrication Engineers Annual Meeting

May 1-4, 1989 (S. Jahanmir-Ceramics)

1400 attendees

This is the largest Tribology technical meeting which is held every year. It brings together a large number of people involved in various aspects of tribology, including research, education, sales, marketing, and development. It also includes an industry exhibit.

Third International Conference on Fundamentals of Fracture May 26-June 16, 1989, (Robb Thomson-Laboratory office), Trieste, Italy 30 attendees

Workshop organizers through the auspices of the International Centre of Theoretical physics on the subject on fundamentals of fracture. 
Second International Conference on Hot Isostatic Pressing - Theory and Applications

June 7-9, 1989 (R.J. Schaefer-Metallurgy)

115 attendees

Technical symposium on advances in hot-isostatic pressing.

Third International Conference on Fundamentals of Fracture

June 19-24, 1989, (Robb Thomson-Laboratory Office), Irsee, W. Germany 120 attendees

This conference explored the developments on fracture fundamentals for the last three years. Participants were from the disciplines of mechanics, physics, chemistry, metallurgy and ceramics

TTCP Ceramic Matrix Composites Workshop

June 22-23, 1989 (D. Cranmer-Ceramics)

15 attendees

The purpose of the workshop was to assess convenient and affordable room temperature test techniques for measuring tensile, compressive, and shear strength of ceramic composites. A second objective was to provide some initial, reliable values of these strengths.

VAMAS Steering Committee Meeting

June 28-30, 1989 (L. Schwartz-Laboratory office)

30 attendees

To host the annual meeting of the International VAMAS steering Committee

SDIO/IST-ONR Diamond Technology Initiative Symposium

July 11-13, 1989 (A. Feldman-Ceramics)

305 attendees

Annual meeting sponsored by the SDIO for rviewing the state-of-the-art in all aspects of CVD diamond technology.

Superconductor and Related Materials Session, 1989 Annual Meeting of

Crystallographic Association

July 24-29, 1989 (W. Wong-Ng-Ceramics)

80 attendees

This session reviewed current results of studies of the crystallography of high temperature superconductors.

Photothermal Techniques from Technology to Basic Physics

August 4, 1989 (G. Birnbaum-ONDE)

20 attendees

This seminar introduced various possibilities of the photothermal detection technique for the nondestructive characterization of materials and systems. 
Symposium on Diamond Optics II, at 33rd Annual International Technical Symposium on Optical and Optoelectronic Applied Science and Enqineering August 7-8, 1989 (A. Feldman-Ceramics)

100 attendees

This meeting was the principal SPIE meeting concerned with diamond as an optical material. It covered both the fundamental aspects of CVD diamond processing, structure and properties as well as applications of diamond and diamondlike carbon.

Enqineering Foundation Conference on Performance of Dental Biomaterials Based on Engineering and Statistical Methods August 13-18, 1990 (J. Tesk-Polymers), Santa Barbara, CA 25 attendees

Conference covered an analysis of interactions between dental standards organizations and industry.

Gordon Research Conference

August 14-18, 1990 (J. Antonucci-Polymers), New Hampton, $\mathrm{NH}$

101 attendees

Intelligent Sensors for Atomization Processing of Molten Metals and Alloys August 28, 1989 (L. Mordfin-ONDE)

20 attendees

This seminar introduced the principles of atomization processing of molten metals and alloys and proposed opportunities for developing intelligent sensors for monitoring and control of the process.

Intelligent Processing for Primary Metals

August 29-30, 1989 (J. Early-Laboratory office)

76 attendees

Reviewed recent advances in sensing, modeling, and process control, identified areas of need in the primary metals industries, and developed a strategy for implementation of research results.

NIST/ONR Workshop on Fracture Computations

September 7-8, 1989 (G.S. White-Ceramics and R.M. Thomson-Laboratory office) 25 attendees

The purpose of this workshop was to review the current status of electronic-, atmosistic-, and micro-scale models for describing the fracture of brittle materials. 
Symposium on Applications of Probability Theory to Polymer Science

September 18-19, 1989 (J. Douglas-Polymers)

76 attendees

Symposium sponsored by the Polymers and Applied Mathematics Division of NIST. Methods such as path integrals, fractals, Levy statistics and linear response theory were applied to polymeric problems and to membranes.

Materials Science Symposium

January 14-15, 1988 (L. Schwartz-Laboratory office)

150 attendees

To honor the 60th birthday of Dr. John Cahn.

Fatique Data Workshop

January 19-22, 1988 (H. McHenry-Fracture \& Deformation)

35 attendees

Addressed the collection, documentation, evaluation, and dissemination of fatigue data. Reviewed existing databases in the United States, Europe, and Japan and discussed documentation standards to permit the interchangeability of fatigue data.

VAMAS steering Committee Meeting

January 22-23, 1988 (L. Schwartz-Laboratory office)

30 attendees

To host the annual meeting of the international VAMAS steering Committee.

Engineered Materials for Advanced Friction and Wear Application

March 1-3, 1988 (A. Ruff-Ceramics)

200 attendees

Application of engineered material to tribological situations.

Workshop on Microstructure and Macromolecular Research with Cold Neutrons April, 1988 (C. Glinka; J. Gotaas-Reactor Radiation)

160 attendees

To inform the scientific and industrial community about the new cold neutron research capabilities at the CNRF and allow them to participate in the design and scientific planning of this new national center.

Low Temperature Structural Materials and Standards Workshop

May 26-27, 1988 (R.P. Reed-Fracture \& Deformation), Tokyo, Japan

33 attendees

Establish international standards and test methods for structural alloys at liquid helium temperature to support the development of superconducting fusion energy magnet devices. 
Gordon Research Conference on Tribology

June 20-24, 1988 (S. Hsu-Ceramics)

130 attendees

Review of most recent research in the field of tribology.

Conference on Thin Film Neutron Optical Devices

August, 1988, (C. Majkrzak-Reactor Radiation), San Diego, CA

50 attendees

Part of a symposium by the International Society for Optical Engineering to present and discuss the latest results in supermirrors, multilayer

monochromators, polarizers and beam guides which are a key to the development of future cold neutron and $x$-ray scattering instrumentation.

Workshop on Intelligent Processing of Materials

August 30-September 1, 1988 ( $T$. Yolken-ONDE)

56 attendees

To define the specific materials processes upon which the NIST Program should focus and to discuss suitable approaches for accomplishing the work.

NIST Workshop on Intelligent Polymer Processing

August 31-September 1, 1988 (A. Bur-Polymers)

25 attendees

To assess the needs of the U.S. polymer processing industry in developing inteligent polymer processing technology.

Mechanical Failures Prevention Group - 43 rd Meeting. "Advanced Technology in Failure Prevention"

October 3-6, 1988 (T. Shives-Metallurgy), San Diego, CA

120 attendees

Technical symposium on techniques for failure analyses and prevention.

Conference on Model Instrumentation and Analysis Techniques

October 6-8, 1988 ( $\mathrm{J}$. Tesk-Polymers)

50 attendees

Conference co-sponsored by NIST and Academy of Dental Materials to provide a useful overview of the dental materials researchers on the application and use of some modern measurement and analysis techniques.

Materials Science of High $T_{c}$ Superconductors: Magnetic Interactions October 11-13, 1988 (L. Bennett-Metallurgy) Co-sponsored by NASA 85 attendees

Technical symposium on recent advances in production and testing of high temperature superconductors. 
Computerization of Welding Information

October 19-21, 1988 (T. Siewert-Fracture \& Deformation)

63 attendees

Review the recent advances in software for welding application and develop a list of user needs to guide future software development.

Eleventh Cryogenic Structural Materials Workshop

October 18-19, 1988 (R.P. Reed-Fracture \& Deformation), Colorado Springs, CO 50 attendees

To review, identify, and discuss important issues relevant to the advancement of structural devices for fusion energy developments.

4 th U.S. -Japan Workshop on Dielectric and Piezoelectric Materials

October 30-November 2, 1988 (S.W. Freiman-Ceramics)

35 attendees

The main purpose of this workshop was to inform U.S. researchers on some recent Japanese research developments in dielectrics and piezoelectrics. The workshop also addressed topics in electrooptics, substrates and packaging, and superconductors.

Four U.S. -Japan Workshops on Dielectric and Piezoelectric Materials

October 31-November 2, 1988 (S. Freiman-Ceramics)

75 attendees

Cooperative summary of research results on electronic materials.

Workshop on Neutron Methods for High $\mathrm{T}$. Superconductors

November 3-4, 1988 (J. Stalick-Reactor Radiation)

30 attendees

Review of neutron methods as applied to superconductor characterization.

Commemerative Conference to Celebrate the 75th Anniversary of the Founding of the Metallurgy Division of NIST

November 10, 1988 (E.N. Pugh-Metallurgy)

120 attendees

To recognize historic significances of the founding of the Metallurgy Division.

Elastic Anisotropy in Composites

December 5, 1988 ( $T$. Yolken-ONDE)

20 attendees

This seminar described a test-bed for the investigation of anisotropic media, such as composites. 
Unit

Laboratory office

Ceramics

Materials Reliability

Polymers

Metallurgy

Reactor Radiation

\section{$\underline{\text { Staff }}$}

8

18

7

11

25

2

71 *
Memberships

15

67

12

33

96

7

230

*Includes: 32 chairs and vice chairs

1 secretary

1 director

\section{Representation}

\section{Organization}

American National Standards Institute

American Nuclear Society

American Society for Testing and Materials

Department of Defense/Technical Coordination

Electronic Industries Association

International Institute of Welding

International organization for Standardization

Joint Committee on Powder Diffraction Standards

National Association of Corrosion Engineers

Safety Glazing Certification Council

Technical Association of the Pulp and Paper Industry

Versailles Project on Advanced Materials and Standards 


\section{RESEARCH DISSEMINATION}

FY 1990

\begin{tabular}{|c|c|c|c|c|c|}
\hline UNIT & $\begin{array}{l}\text { PAPERS } \\
\text { PUBLISHED }\end{array}$ & $\begin{array}{l}\text { TALKS } \\
\text { INVITED }\end{array}$ & PATENTS* & SRMS* & MONOGRAPHS* \\
\hline LABORATORY OFFICE & 16 & 38 & --- & --- & --- \\
\hline \multicolumn{6}{|c|}{ OFFICE OF NONDESTRUCTIVE } \\
\hline EVALUATION & 5 & 6 & --- & --- & --- \\
\hline CERAMICS & 193 & 150 & 6 & 4 & 2 \\
\hline MATERIALS RELIABILITY & 84 & 26 & 1 & 3 & --- \\
\hline POLYMERS & 167 & 111 & 8 & 3 & --- \\
\hline METALLURGY & 149 & 106 & 6 & 4 & 1 \\
\hline REACTOR RADIATION & 132 & 39 & $=--$ & --- & $\underline{---}$ \\
\hline TOTAL & 746 & 476 & 21 & 14 & 3 \\
\hline
\end{tabular}

"Listing on following page. 
Patents Received or Pending

1988-1990

1990

A Process for the Controlled Preparation of a Composite of Ultrafine Magnetic Particles Homogeneously Dispersed in a Dielectric Matrix

Applied For

J. Ritter (Ceramics), R. Shull (Metallurgy)

Novel Synergistic Additive Packages Containing High Molecular Weight

Antioxidants for High Temperature Lubricants

Disclosure Filed

S. Hsu, J. Perez, C. Ku, Y. Zhang (Ceramics)

Low Energy (Thermal) Neutron Absorbing Glass

Disclosure Filed

D. Blackburn, C. Stone, D. Cranmer (Ceramics)

Phosphorous Containing Boundary Lubrication Antiwear Additives for Silicon Nitride Ceramic Materials

Disclosure Filed

R. Gates, S. Hsu (Ceramics)

Process for Elimination of Twins in Perovskite-Type Superconducting Single Crystals

Disclosure Filed

D. Kaiser (Ceramics), F. Gayle (Metallurgy)

A Method for Fabrication of Materials from Nano-Sized Particles Using High Pressure and Cryogenic Temperatures

Disclosure Filed)

(A. Pechenik, G. Piermarini (Ceramics)

Method to Make Transparent $\mathrm{Si}_{3} \mathrm{~N}_{4}$ at Low Temperature Without Additives Disclosure Filed

A. Pechenik, G. Piermarini, S. Block (Ceramics)

Coating of Reinforcing Agents of Ceramic Composites by Colloidal Processing Applied For

S. Malghan (Ceramics)

Nondestructive Ultrasonic Evaluation of Formability of Metallic Sheets Applied For

A.V. Clark (Materials Reliability)

R.B. Thomson (Iowa State University)

Superconductor - Polymer Composites

Patent No. 4,954,481

A.S. DeReggi, C.K. Chiang, G.T. Davis (Polymers and Ceramics) 
Intaglio Ink Resins Which Cure by Oxidation in Air

Disclosure Filed

B. Dickens, B.J. Bauer (Polymers)

Nanocomposite Material for Magnetic Refrigeration and Superparamagnetic Systems Using the Same

Applied For

R. Shull, L. Bennett, L. Swartzendruber (Metallurgy)

Method and Apparatus for Performing Non-Contact Measurements of Temperature, Conductivity, Diameter and Velocity

Applied For

A.H. Kahn, S.J. Norton, M.L. Mester (Metallurgy)

Predetermined Concentration Graded Multi-Layer Alloys and Method for Production Thereof

Applied For

D. Lashmore (Metallurgy)

Magnetron Sputtering Apparatus and Process

Patent No. 4,851,095

D. Lashmore (Metallurgy)

\section{$\underline{1989}$}

Buffered Cell for Sintering of High TC Thallium Containing Ceramics

Disclosure filed

L. Cook (Ceramics)

Self Lubricating Ceramic Matrix and Metal Matrix Composite

Disclosure filed

M. Peterson, A. Ruff, S. Jahanmir (Ceramics)

A Process for the Fabrication of Ceramic Monoliths

(By Laser Assisted CVI)

Applied For

J. Ritter (Ceramics)

Ultraviolet Transmitting Glass for Ring Dye Laser

Disclosure filed

D. Blackburn, D. Cranmer, D. Kaufman (Ceramics)

Diamond Coated Infrared Transmitting Optics

Disclosure filed

A. Feldman, E. Farabaugh (Ceramics)

Systems for Monitoring Changes in Elastic Stiffness in Composite Materials Patent No. 4,499,770, February 19, 1985

R. Kriz (Fracture and Deformation) 
Non-Aqueous Dental Cements Based on Dimer and Trimer Acids

Patent No. 4,832,745

$\mathrm{J}$. Antonucci (Polymers)

Thermal Technique for Determining Interface and/or Interply Strength in Composites

Applied For

W. Wu (Polymers)

Calcium Methaphosphate Filled Compositions

Applied For

J. Antonucci, B. Fowler, S. Venz (Polymers)

Resin-modified Glass Ionomer Dental Cements

Disclosure Filed

$\mathrm{J}$. Antonucci, J. Mckinney, J. Stansbury (Polymers)

Synthetic Dental Compositions and Bonding Methods

Applied For

J. Stansbury (Polymers)

An Optical Sensor for the Measurement of Molecular Orientation and Viscosity of Polymeric Materials Based on Fluorescence Radiation

Disclosure Filed

A.J. Bur, R.E. Lowry, S.C. Roth, C.L. Thomas, F.W. Wang (Polymers)

Trivalent Chromium Deposition

Patent No. 4,804,446, February 14, 1989

D.S. Lashmore, E. Namgoong, I. Weishaus (Metallurgy)

Nanocomposite Material for Magnetic Refrigeration

Disclosure Filed

L.H. Bennett, R.D. Shull, L.J. Swartzendruber (Metallurgy)

New Matrix Approach to Crystal Symmetry

Applied For

A. Mighell; V. Himes (Reactor Radiation)

\section{$\underline{1988}$}

Aluminum Hydroxides as Solid Lubricants

Patent No. 4,919,829

R. Gates, S. Hsu (Ceramics)

High Pressure Process for Producing Transformation Toughened Ceramics Patent No. 4,771,022, September 13, 1988

S. Block, G. Piermarini (Ceramics)

Fibrous Monolithic Ceramic and Method for Production

Patent No. 4,772,524, September 20, 1988

w. Coblenz (Ceramics) 
Ultraviolet Transmitting Glass for $308 \mathrm{~nm}$ Ring Dye Laser

Disclosure Filed

D. Blackburn, D. Kauffman, D. Cranmer (Ceramics)

Novel Process for the Preparation of Fiber Reinforced Ceramic Matrix Composite Disclosure Filed

W. Haller, U. Deshmukh (Ceramics)

Dielectric Phantom Material

Applied For

M. Broadhurst, C. Chiang, G. Davis (Polymers)

Oligomeric Adhesives

Applied For

G. Brauer; C. Lee (Polymers)

Radiopaque Polymers Useful as Components for Radiopaque Materials Applied For

G. Brauer, J. Stansbury, J. Tesk (Polymers)

Polymeric Denture Reline Materials

Applied For

R. Muller, J. Antonucci (Polymers)

Resin-modified Glass Ionomer Dental Cements

Disclosure Filed

J.M. Antonucci, J.E. Mckinney, J.W. Stansbury (Polymers)

Method of determining subsurface property value gradient

Patent No. 4,765,750 - August 23, 1988

H.N.G. Wadley (Metallurgy)

Concentration Gradient Alloys

Disclosure Filed

D.S. Lashmore and M.P. Dariel (Metallurgy)

Trivalent Chromium

Issued October 1988

D.S. Lashmore, E. Weisshaus, E. Namgoong (Metallurgy) 


\section{SRMS PRODUCED \\ 1990}

SRM Research Report - A Catalyst Package for Lubricant Oxidation II

(Ceramics)

SRM 1084 a Wear Metals in $0 i l(100 \mathrm{ppm})$

(Ceramics)

SRM 1085a Wear Metals in Oil (300 ppm)

(Ceramics)

SRM 1836 Total Nitrogen in Lubricating Base oil

(Ceramics)

SRM 2092 Charpy V-Notch Low Energy Test Blocks

(Materials Reliability)

SRM 2096 Charpy V-Notch High Energy Test Blocks

(Materials Reliability)

SRM 2098 Charpy V-Notch Super High Energy Test Blocks

(Materials Reliability)

SRM 388p Isobutylene-Isoprene (Butyl) Rubber Standard for Mooney Viscosity (Polymers)

SRM 386k Styrene-Butadiene (Type 1500) Rubber Standard for Standard Rubber Formulations

(Polymers)

SRM 705a Polystryne

(Polymers)

SRM 1476a Polyethylene Melt Flow Rate

(Polymers)

SRM 1477 Polypropylene Melt Flow Rate

(Polymers)

SRM 1321; 1322; 1323; 1357; 1358; 1359; 1360; 1361a;1362a; 1363a; 1364a 1375;

Nonmagnetic Coating on Magnetic Substrate (Copper and Chromium on Steel)

(Metallurgy)

SRM 1331a; 1332a; 1333a; 1334a; 1335a; 1336a; 1337a; 1338a; 1339a Magnetic Coating on Magnetic Substrate (Nickel on Steel)

(Metallurgy) 
SRM 1371; 1372; 1373; 1374 Gold Coating on Glass Sealing Alloy, ASTM Designation F-15, FE-53, NI-29 and Co-17

(Metallurgy)

SRM 1375, 1376, 1377, 1378, 1379, 1380, 1387 Gold Coating on Nickel

(Metallurgy)

\section{MONOGRAPHS}

1990

Phase Diagrams for Ceramists-Volume VII, the American Ceramic Society, Westerville, $\mathrm{OH}$

L. Cook, H. McMurdie (Ceramics)

Phase Diagrams for Ceramists-Volume VIII, the American Ceramic Society, Westerville, $\mathrm{OH}$

B. Mysen, H. McMurdie, H. Ondik (Ceramics)

Materials Chemistry at High Temperatures - Characterization, Processing and Performance, Editor J.W. Hastie (Metallurgy), Humana Press, N.J. 
APPENDICES 
1990 PANEL MEMIBERS

APPENDIX A

Prof. Bernard H. Kear

Chairman (1993)

Department of Mechanics and Materials Science

College of Engineering

Rutgers University

PO Box 909

Piscataway, NJ 08855-0909

(201) $932-2245$

Prof. Thomas W. Eager (1993)

Massachusetts Institute of Technology

Room 4-136

77 Massachusetts Avenue

Cambridge, MA 02139

(617) 253-3229

Prof. William W. Graessley (1993)

Department of Chemical Engineering

Princeton University

Princeton, NJ 08544

(609) 258-5721

Prof. Robert E. Green (1992)

Materials Science and

Engineering Department

The Johns Hopkins University

Baltimore, MD 21218

(301) 338-6115

Dr. Robert E. Hefner (1993)

Director and CEO

Michigan Molecular Institute

1910 West St. Andrews Road

Midland, MI 48640

(517) 832-5555

Dr. Peter Juliano (1991)

Manager, Polymer Physics and

Engineering Laboratory

General Electric Corporate

Research and Development

P.O. Box 8

Schenectady, NY 12301

(518) 387-5874
Prof. Ronald M. Latanision (1993)

Materials Processing Center

Massachusetts Institute of

Technology

77 Massachusetts Avenue

Cambricge, MA 02139

(617) 253-4697

Dr. Robert A. Laudise (1992)

Director

Materials Chemistry Research Lab

AT\&T Bell Laboratories

Room 1A-264

600 Mountain Avenue

Murray Hill, NJ 07974

(201) 582-6220

Dr. Richard A. Page (1993)

Department of Materials and Mechanics

Southwest Research Institute

6220 Culebra Road

Post office Drawer 28510

San Antonio, TX 78228-0510

(512) $522-3252$

Dr. Neil Paton (1992)

Program Manager

NASP Materials and Structures

Technology

Rockwell International Corp.

Rocketdyne Division

6633 Canoga Avenue, Mail stop WBO 7

Canoga Park, CA 91303

(805) 371-7013

Dr. Arthur L. Ruoff (1992)

Professor of Materials Science and Engineering

Department of Materials Science and Engineering

Bard Hall

Cornell University

Ithaca, NY 14853

(607) 255-4161 
Dr. Maxine L. Savitz (1993)

Director, Ceramic Components Div.

Garrett Processing Company

19800 South Van Ness Avenue

Torrence, CA 90509

(213) 618-7569

Dr. Harvey $w$. Schadler (1993)

Manager, Materials Research Center

General Electric Corporate

Research and Development

PO BOX 8

Schenectady, NY 12301

(518) 381-6100

Dr. Cecil M. Teller (1992)

Corporate Science officer

Texas Research International, Inc. 9063 Bee Caves Road

Austin, TX 78733-6201

(512) 263-2101

Dr. Bernhard R. Tittmann (1993)

Department of Engineering Science Pennsylvania State University

University Park, PA 16802

(814) 865-7827

Dr. Michael K. Wilkinson (1991)

Solid State Division

Oak Ridge National Laboratory

PO BOX 2008

Oak Ridge, TN 37831-6024

(615) 574-2592 


\author{
An Evaluative Report on the \\ Materials Science and Engineering Laboratory
}

\title{
Panel Members
}

Francois A. Padovani, Texas Instruments Inc., Chairman

Robert E. Green, The John Hopkins University

Edmund G. Henneke II, Virginia Polytechnic Institute and State University

Ian F. Hughes, Inland Steel Company

Peter Juliano, General Electric

Bernard H. Kear, Rutgers University

Robert A. Laudise, AT\&T Bell Laboratories

Neil Paton, Rockwell International Corporation

R. Byron Pipes, University of Delaware

Arthur L. Ruoff, Cornell University

Maxine L. Savitz, Garrett Processing Company

Richard S. Stein, University of Massachusetts

Cecil M. Teller, Texas Research Institute

Charles M. Vest, University of Michigan

Julia R. Weertman, Northwestern University

Albert R.C. Westwood, Martin Marietta Corporation

This report submitted for the Panel by the Chairman, Francois A. Padovani, is an annual assessment of the activities of the Materials Science and Engineering Laboratory (MSEL) based on a meeting of the Panel on February 1 $2,1990$.

\section{Functions of the Laboratory}

MSEL develops and maintains the scientific competences and experimental facilities necessary to provide the Nation with a central basis for uniform physical measurements, measurement methodology, and measurement services fundamental to the processing, characterization, properties and performance of materials, and to other essential areas in materials science. MSEL provides government, industry, universities and consumers with standards, measurement methods, data, and quantitative understanding concerning metals, polymers, ceramics, composites, optical materials, and mono-equilibrium materials. MSEL characterizes the structure of materials, chemical reactions and physical properties which lead to the safest, most efficient uses of materials, improve materials technologies, and provide the basis for advanced material technologies in basic and high-technology industries. MSEL obtains accurate experimental data on behavior and properties of materials under service conditions to assure effective use of raw and manufactured materials, and provides technical information such as reference data, materials measurement methods, and standards, to processors, designers, and users for selection of cost-effective combinations of materials processes, designs, and service conditions. MSEL makes extensive use of specialized test facilities such as the unique NIST reactor and cold neutron research facilities to develop 
neutron measurement methodology, to develop sophisticated structure characterization techniques, reference data, and standards. MSEL participates in collaborative efforts with other NIST organizational units in interdisciplinary developments in materials science. Finally, MSEL disseminates generic technical information from the Divisions to private and public sector scientific organizations through special cooperative institutional arrangements and through conventional distribution mechanisms.

\section{Introduction}

The Laboratory consists of five technical Divisions: Ceramics, Materials Reliability (located at the Boulder, Colorado Laboratories), Polymers, Metallurgy, and Reactor Radiation; and one independent office: Nondestructive Evaluation, which sponsors cross-cutting research throughout NIST. During fiscal year 1989, the Laboratory had a total operating budget of approximately $\$ 47.0$ million, including capital equipment acquisitions. MSEL has a NIST staff of 380 , of which 89 percent are in scientific or technical support positions. Seventy percent of scientists and engineers have PhD degrees.

In addition to the NIST staff, the Laboratory hosted 408 visiting scientists and engineers during 1989. These scientific and engineering visitors were involved in collaborative research or utilization of the special Laboratory facilities (e.g., research reactor). These visitors represented U.S. industry, academe, other Federal agencies, and foreign institutions. Their stay at MSEL ranged from several weeks to the entire year, and their salaries and associated costs were covered by their parent organizations.

During the past year, the Laboratory has continued to expand facilities and research opportunities in spite of the absence of new initiative funding for fiscal year 1989. The construction of the new buildings (guide hall, office/laboratory, and compressor building) for the Cold Neutron Research Facility (CNRF) was completed on time and within budget. The neutron guide tube installation began in June with the subsequent installation of the first three guides. Commitments for the instrumentation construction by industry and other non-NIST organizations total in excess of $\$ 3.0 \mathrm{M}$ for three instruments. The CNRF Program Advisory Committee (PAC) met for the first time and is expected to play a critical role in advising NIST on utilization of the national user facility.

With first year (FY 1988) funding from the high performance composite initiative, a strong start has been made in developing and equipping a polymer composites fabrication facility. Two processing methods, pressure molding and resin transfer molding, had been identified through an industry workshop as the most promising fabrication techniques for the future. Scheduled to be completed by the end of fiscal 1990, many processing components will be operational early in 1990 for the preparation of well-characterized test samples and the investigation of processing science and on-line process control.

The Laboratory has further strengthened its programs through linkages with the private sector. Industrial collaboration has always been one of the major components of NIST's response to its mission. Passage of the Omnibus Trade Act 
has explicitly reinforced the importance of this outreach effort and of the benefits to the national economy derived from working closely with industry. Early collaboration with industry, often coupled with their scientists working directly with NIST staff, provides critical and timely information on industry's measurement-related problems and assures rapid transfer of research results from NIST programs. Through a series of internal and external actions, MSEL has taken the initiative in focusing industry and government attention on the concept of intelligent processing of materials using in-situ sensing and a computer-based approach to control the evolution of materials microstructures. Research efforts in advanced process control sensors has resulted in the verification of proof of concept for a number of specific applications. Efforts to transfer these sensor concepts to the mill floor has led to substantial industry participation in field trials of sensor systems in production environments.

\section{Materials Science and Engineering Laboratory Overview}

Quality of staff and research performed are excellent. Morale of the staff is very high. Average age has dropped from 48 years two years ago to 46 years, a proof of the accomplishments of the personnel initiative that began a few years ago. Considerable effort has been expended to develop plans to enhance industry interaction following last year congress redirection of NIST. Many industrial workshops have been held to identify actual industry needs.

Continuous outstanding progress of the implementation of the cold neutron facility building is certainly the best evidence of the high degree of professionalism and excellence existing through out the MSEL organization.

These achievements, along with many more demonstrated accomplishments in metals, ceramics, polymers, and composites are positive proof of the excellent performance of MSEL Divisions.

Separate reviews of each division by a sub-panel was again used this year. Each panel established its own report which was reviewed at the panel meeting. The present report will address highlights of these reports which are attached as appendices and focus the discussion on issues common to the MSEL Divisions.

\section{Technical Review of Divisions}

The panel was charged this year to review the quality of the technical achievements, the direction of the planned initiatives, the utilization of the resources both human and physical, and the extent of industry interactions.

\section{Ceramics}

Function of the Division

The Division addresses fundamental and applied research and standards issues pertinent to the advanced ceramics industry through development and dissemination of models, standard test methodologies, standard reference materials and standard reference data. Activities are focused on structural 
applications such as in heat engines and heat exchangers and on functional applications such as in optical and electronic devices. Extensive and continuing contacts with standards organizations, industrial consortia, technical societies, and industrial firms ensure that the efforts are focused on scientific issues important to problems generic to the advanced ceramics industry. The paramount scientific issues are those concerned with the relations between processing and structure at the atomic, molecular and microscale levels, and the ways in which those structures affect the performance of the ceramics. Primary industrial concerns are cost, durability, and reliability. These concerns are addressed through programs aimed at the development of standards, predictive models and data of mechanical, tribological, electronic and optical performance. Specifically, prestandards research activities are pursued in surface and bulk fine powder characterization, synthesis of ceramic powders, development of high temperature tensile measurement techniques, ceramic matrix composites and interface characterization, fracture and crack bridging, technical wear film analysis and wear model development, processing and mechanical properties of superconductors, phase diagrams development for superconductors, surface forces, deposition and defect analysis of diamond films, and synchrotron radiation analysis of photonic materials.

\section{Introduction}

The primary impediments to the growth of the advanced ceramics industry are lack of reliability and high cost of ceramic components and devices. The Division programs address these issues through a broad range of research projects which focus on understanding the role of processing on properties as well as behavior mechanisms.

Fine powders (approximately 1 micron) from which ceramics are made are crucial in determining the cost and final properties of a product. For this reason, the Division has developed a strong capability in the synthesis, characterization and processing of powders. Through the auspices of the International Energy Agency (IEA), the Division has been the focal point for an international assessment of powder characterization techniques as well as leading the participation of U.S. industries. On a fundamental level, efforts are focused on the nature and effects of powder surface chemistry on agglomeration and ease of processing. To develop this understanding, the Division has established a solid state nuclear magnetic resonance (NMR) laboratory as well as a slurry Characterization Laboratory. Processing studies have continued for both monolithic and ceramic matrix composites.

Improvements in the reliability of advanced ceramics, whether for structural or functional applications, require a mechanistic understanding of the modes of failure to which a ceramic is susceptible. To further the impact in this area, Laboratory efforts are focused on the understanding of microstructural features which control brittle fracture and high temperature creep.

Durability issues for structural ceramics, in addition to long-term mechanical properties, have been addressed through the tribology program which is focused on developing an understanding of the role of microstructure, surface reactions and lubrication on the wear of advanced materials. 
Efforts in the functional ceramic field have included, for electronic applications, the continuation of processing-property studies on piezoelectric materials as a major effort on high $T_{c}$ superconducting ceramics. Research in the latter field has encompassed phase diagram development for lanthanide series substitutions in the YBaCuo system as well as studies of the relationships of processing to microstructure and properties.

Research in the optical materials area has included the development of techniques of deposition and analysis of diamond films which are expected to find application as protective coatings on a variety of detector windows.

The Division has served as a link between academically oriented fundamental research and the applied needs of industrial technology. To fulfill this function, the Division interacts intensively with both communities to access and utilize state-of-the-art science and to apply this science to the implementation of advanced ceramics. Collaborative programs with academic institutions that are conducting ceramic research programs have resulted in the active participation of 28 Guest Scientists in the Division's program. Industrial support for the program has included both direct funding as well as contributions of goods and services. Currently, 31 Research Associates from industry are participating in Division research projects.

\section{Assessment Summary}

The Division is admirably fulfilling its objectives and continues to be well managed. The Division has made a successful transition toward a focus on modern ceramics with an increased sensitivity to industry customer needs. Its work is excellent and world class.

Examples of recent achievements include its phase equilibria and superconductivity studies, the discovery of a new high temperature lubricant, the completion of the international round robin on powder characterization, the measurement of the forces between silica-silica and mica-silica using NIST's surface force facility, and the development of a new diffraction technique which characterizes size and shape of ceramic powders.

The Division's great strengths and reputation in phase equilibria must not be lost. Robert Roth who has recently retired should be replaced and an effort to generate industrial consortium support for experimental phase equilibria work should be mounted.

The new high temperature lubricant. must be exploited via patent protection, and technology transfer and used as a bellwether example of NIST in the service of American competitiveness.

\section{Materials Reliability}

Functions of the Division

The Division conducts materials research to improve the quality, reliability and safety of the Nation's infrastructure, industrial projects, and equipment. The Division fosters the industrial use of advanced materials by developing 
techniques to measure their quality and analytical models that relate quality to service performance and reliability. The Division develops measurement methods, sensors, and nondestructive evaluation techniques for process control, quality assurance, and in-service inspection. The Division develops measurement methods, test standards, standard reference materials and reference data on the physical and mechanical properties of materials, particularly at low temperatures. The Division develops and maintains competence in three interdisciplinary fields related to reliability: fracture mechanics, nondestructive evaluation, and joining technology. The Division provides research and technical services to other government agencies and to industry including materials evaluations, failure analyses, reliability and safety assessments, data compilations, consultation and use of NIST facilities.

Introduction

The Materials Reliability Division, formerly the Fracture and Deformation Division, conducts materials research to improve the quality, reliability, and safety of industrial projects and the Nation's infrastructure. The research performed fosters the use of advanced materials in commercial products by improving confidence in their service performance. These goals are pursued by developing measurement technology for:

1. process controls which improve the quality, consistency and producibility of materials

2. nondestructive evaluation (NDE) which assures the quality of finished materials and products

3. fitness-for-purpose standards which relate material quality to reliability and safety

4. materials evaluation for severe applications, particularly for service at cryogenic temperatures

The interdisciplinary staff is organized into specific research groups in the general areas of materials performance, properties, and processing. Each group is headed by a recognized expert who provides a focal point for industrial cooperations, scientific interactions, and technology transfer. studies in nonlinear fracture mechanics, mechanical behavior, and physical property measurements and modeling increase the understanding of materials behavior. Programs in fracture mechanics, nondestructive evaluation, and welding technology contribute to structural safety. Improvements in fitnessfor-service criteria, quality control sensors, and deformation processing raise industrial productivity.

In support of the long range plan of the Materials Science and Engineering Laboratory, new programs focus on advanced materials with high commercial potential and on automated processing, which is the key to improved productivity in the materials industry. In addition to Laboratory sponsored research, the Division conducts materials research for other government agencies and provides technical services to industries, universities, and 
other scientific laboratories. Programs for other agencies are usually related to the safety of structures, pressure vessels and piping, transportation equipment, and cryogenic systems. The Division's technical services include materials evaluation, failure analysis, and consultation.

Assessment Summary

The Division has demonstrated over the years an excellent working relations and accomplishments in joint efforts with industry. Example of such efforts are the application of electromagnetic acoustic transducers (EMAT) systems for nondestructive determination of the formability index of thin sheet steel and detection of flaws in railroad wheels.

A recent major accomplishment has been to add to the cryogenic materials data base the properties of aluminum-lithium alloys and copper, and the design and construction of a unique 500 metric-ton-load capacity facility for tensile and compression testing at cryogenic temperatures.

The fracture mechanics and fracture physics groups have redirected their efforts from metals and alloys to composite materials and electronic packaging. The composite materials effort is directed to the understanding of local damage that deteriorate strength and stiffness, but does not necessarily trigger fracture. The electronic packaging effort is aimed at developing techniques for characterizing fracture behavior in thin films and multilayered materials.

The Division has increased its efforts both in development of ASTM test methods and development of new standards. The large number of cooperative efforts the Division has with industrial organizations testifies to the fact that their current and future directions are directly in line with MSEL initiatives. Future directions should focus on non-intrusive methods and cryogenic properties of materials. Both of these initiatives would build on existing expertise and capabilities.

\section{Metallurgy}

Functions of the Division

The Division studies metals and alloys in order to foster their economical processing and their safe and efficient use. The Division develops and maintains competence in three general areas: (1) metals processing with special emphasis on sensors for process control, (2) characterization of advanced materials with emphasis on metal matrix composites, intermetallic alloys, and superconductors, and (3) properties and performance of metallic materials with emphasis on the durability and structural integrity of metals. The Division serves as a national resource of metallurgical information through the Alloy Phase Diagram Program with ASM International, and the Corrosion Data Program with NACE. The Division provides consultation and assistance to other government agencies and standards organizations in the development of necessary test methods and standards. 
In response to NIST's mandate to assist in increasing the Nation's industrial competitiveness, the emphasis in measurement science continues to evolve towards processing, specifically to process sensors and, in some instances, to process modeling and automated process control. The focus on processing has also led to a more direct interaction with industry, as evidenced by the consortium for powder atomization and other joint programs. In materials characterization, the thrust is toward new, advanced materials, including metal matrix composites, intermetallic alloys, and nanocrystalline magnetic materials, as well as high $T_{c}$ superconductors. The Corrosion Data Program (with NACE) has replaced the successful Alloy Phase Diagram Program (with ASM International) as the Division's largest data activity.

The Division's major programs are grouped into three major categories: Metals Processing and Sensors, Characterization of Advanced Materials, and Data and SRM Programs.

Powder processing represents a major thrust, with programs involving both powder atomization and consolidation. The former centers on the Division's high pressure inert gas atomizer, and is a cooperative effort with two other NIST Centers (Chemical Engineering and Manufacturing Engineering) and three companies, via a consortium. The program is directed towards the measurement and real-time control of powder size, such control being important for efficient consolidation and to obtain desired properties, particularly in RAP applications. The later studies powder consolidation phenomena by focusing on hot isostatic pressing of Ti-Al intermetallics. The goal of this DARPA supported program is to develop intelligent processing systems for fabricating difficult materials such as titanium aluminides into near net shape components. The immediate NIST role is the development of sensors for monitoring densification in real time.

Metal matrix composites (MMC) represent an important emerging technology in which the Division has a significant effort, cutting across several groups. The bulk of the work so far has dealt with continuous fibers and has focused on the fiber-matrix interface, which controls the properties of these high performance composites. Intermetallic alloys represent another major activity of the Characterization of Advanced Materials program area. HIP studies and alloy electrodeposition are being carried out on Ti-Al alloys, which are potentially important for high temperature structural applications. Although many of the early promising property reports for intermetallics were obtained with single phase materials, further improvements in properties are anticipated using multiphase structures.

The Alloy Phase Diagram Program on binary alloys, conducted cooperatively with ASM International, is drawing to a successful conclusion. The main thrust of the Division's program is now on ternary diagrams, both in evaluation of certain critical systems and in developing a ternary graphics package, and in providing support for other in-house programs such as those described above on MMC and intermetallic alloys. The Corrosion Data Center, formed in cooperation with NACE in response to a critical need for a centralized, computerized database of corrosion data, continued to expand in 1989 . 
Industry support for the development of focused programs addressing critical needs has grown. Emphasis has been placed on knowledge-based expert systems which use artificial intelligence concepts to aid corrosion scientists and engineers in selection of materials for applications in corrosive environments.

\section{Assessment Summary}

Intelligent processing of materials is necessary for a competitive U.S. industry. The Division has established a multidisciplinary group to address powder atomization in a consortium with three industrial companies.

Significant progress has been made in the development of a real time sensor to measure particle size distribution and in the understanding of the atomization process. The panel recommends that the work done on the understanding of atomization be extended to other areas of interest to industry such as plasma spraying and hypersonic jet spraying. The focused effort of the Division in this area should quickly achieve an acknowledged leadership position in the United States.

Sensor development programs have made excellent progress and demonstrate strong industry interaction. The eddy current sensor developed in collaboration with the Aluminum Association has been successfully applied to extruded products and is now being modified to address rolled products.

The Electrodeposition program continued to break new ground with the direct electroforming of the intermetallic AlTi, a potentially significant development in view of the difficulties of fabricating and machining these important high temperature alloys by other techniques.

The ASM-NIST Alloy Phase Diagram Program on binary alloys is drawing to a successful conclusion. The thrust has been shifted to ternary alloys with focus to the increasingly important intermetallic alloys. The main data activity of the Division is currently in the Corrosion Data Center operated in collaboration with the National Association of Corrosion Engineers. The growth of industrial support for this program over the past year has confirmed that this program is meeting a critical national need. Present emphasis on knowledge-based expert systems to aid materials selection seems an excellent choice of directions.

\section{Polymers}

\section{Functions of the Division}

The Polymers Division provides the measurement methods, standards, and data needed for the efficient processing and use of polymers and polymer matrix composites to improve international competitiveness and solve national problems. The Division provides the science base for the industrial development of new polymeric materials and processes. The Division develops measurement methods to predict the electrical, optical, chemical, and mechanical performance of polymers, and composites in service environments. The Division conducts research on the connection between the processing and performance of polymeric materials and provides measurement methods and 
standard materials to control processing. The Division provides measurement methods and unique facilities for determining the physical and chemical structures of polymers. The Division is also involved in the determination of dental and medical materials properties in order to provide the basis for standards, test methods, and improved materials.

\section{Introduction}

The Division is responsible for providing standards, measurement methods, and fundamental concepts of polymer science to assist U.S. industries that produce or use synthetic polymers in essential parts of their business. This broad mission does not change markedly with time, but the specific technical programs within this broad mission must be continually assessed to meet the industry's changing priorities. The Division programs are highly technical and involve a large number of projects in areas of phase diagrams and processing of blends, chemical and mechanical performance of polymers, processing and reliability of polymer composites, electrical performance of polymers, characterization and standards, and dental and medical materials.

Significant changes this year involve the expansion of the research program in polymer matrix composites. While these materials have been used for some time as high performance laminates for the defense and aerospace industries, their use in a wider variety of civilian markets has been inhibited by several technical factors. An important barrier is that the low volume lay-up process used to make very high performance aerospace parts cannot be easily adapted to higher production volumes and lower part costs. Following the recommendations of industry representatives, the NIST program emphasizes study the behavior of polymers in transfer molding or reaction injection molding processes.

A second barrier to the more widespread use of polymer composites is the limited ability to measure and understand the way these materials perform or fail in service. The highly anisotropic properties that allow composites to be tailored for a specific application make their failure behavior very complex. Composite properties are also highly dependent on their processing conditions. This means that a meaningful composites program must integrate the mechanics of composites with an understanding of the material science of the polymer matrix, the fibers, and the influence of process conditions. This is the goal of the next phase of the program.

Technology transfer to industry continues to be a major concern of all of the Division's programs. The most effective method is through direct interaction with individuals from industry who know both their business and technical needs. Many of these interactions come through scientists who collaborate with the Division on technical projects. Last year the Division cooperated with over 130 Research Associates and Guest Scientists who together spent 50 staff years of effort in the laboratories. In addition, many industrial scientists have spent one or two days using specialized equipment developed by Division scientists to explore future research collaboration or to make proprietary measurements on their developmental materials. 
The quantity and quality of technical accomplishments of the Division continue to be very high. The Polymer Division at NIST is probably one of the four strongest polymer physics groups in the United States.

A program of technology transfer with Dupont has been initiated for the study of functionally terminated macromonomers. Copolymerization of macromonomers with conventional monomers has been studied and the resulting copolymers have been evaluated as radiation cured ink resins.

In a cooperative program with Union Carbide, the thermal pulse technique for measuring charge distribution in polymer films has been successfully applied to characterize charge accumulation in films especially prepared for electrical insulation.

The 10-meters SAXS Facility had active outside users which included 4 industrial laboratories, 3 academic institutions, and 3 Federal laboratories.

Two new polymer composite programs were developed in answer to last year's Panel stress of the importance of the fiber-matrix interface. The possible use of neutron reflectance in studying composite interfaces is being evaluated and is strongly encouraged by the Panel.

The use of finite element modeling and continuum mechanics in analyzing the processing and performance of composites is an essential activity. The Division has the advantage of appreciable computer resources which are necessary for such analyses. Even greater effort could be supported by available computers, and the Panel believes it would be cost effective to invest in such personnel.

A patent was applied for on the use of microwave generated gas plasmas for sterilization of dental and medical instruments in as short as 1-2 minutes at temperatures near or below $60 \mathrm{C}$. Commercialization of this technique is strongly encouraged by the Panel.

\section{Reactor Radiation}

\section{Functions of the Division}

The Division operates the research reactor (NISTR) reliably, safely, and in a cost effective manner. The Division develops and operates the CNRF as a National User Facility, providing unique measurement capabilities to U.S. researchers. The Division conducts programs in materials research using cold and thermal neutron methods, while developing and maintaining state-of-theart instrumentation to ensure the best utilization of the NISTR and CNRF as NIST and national resources. Through cooperative arrangements, the Division collaborates with and provides facilities, coordination, guidance, and technical services for all NIST, other government agencies, universities and industrial programs utilizing the NIST reactor for materials research, nondestructive evaluation (NDE), chemical analysis, neutron standards, dosimetry, radiation metrology, and isotope production. 
The responsibilities of the Reactor Radiation Division are threefold: to operate the NISTR in a cost-effective manner while protecting the public safety; to conduct a program of materials research using neutron methods, while developing and maintaining state-of-the-art instrumentation to ensure the best utilization of the NISTR and CNRF as NIST national resource; and to develop and operate the CNRF as a National User Facility, providing unique measurement capabilities to U.S. researchers.

The Division in collaboration with other researchers in MSEL other NIST Centers, and many outside organizations, develops and applies neutron methods to a broad range of problems of national concern. These include the use of activation and other nuclear methods for chemical analysis, the characterization of the submicroscopic structure and dynamics of materials (e.g., hydrogen in metals, polymers, ceramics, alloys, magnetic materials, amorphous systems, micelles, microporous materials), the determination of residual stresses and texture in materials, the use of neutron radiography to examine large components, the establishment of neutron flux and personnel radiation standards, and the development of a CNRF.

In addition to operating the reactor, the Division is responsible for sample irradiations, both for Activation Analysis and isotope production. Many outside agencies (e.g., FDA, FBI, Treasury, EPA) make use of the activation and analysis capabilities.

An active program of research on materials characterization is carried out, including development and maintenance of a state-of-the-art suite of neutron scattering instrumentation. The emphasis is on the study of new materials of importance to science and technology such as polymer blends, composites, electronic and structural ceramics, chemical catalysts, novel magnetic systems, thin films and interfaces, biological materials, and new metal alloys. This work involves more than 200 researchers from outside the Division, working both collaboratively and independently. At the present time, the NIST reactor has more users than any other facility for neutron research in the United States, even before the CNRF is completed.

A major new element of the Division mission is centered in the Cold Neutron Project, with the goal of providing a critical new measurement capability for U.S. researchers. This multiyear project makes use of the large volume cold source installed into the reactor in 1987 by providing seven neutron guides (analogous to fiber optic light pipes, except for a difference in scale) to conduct large $(6 \times 15 \mathrm{~cm})$ beams into a newly constructed experimental hall that provides $20,000 \mathrm{sq}$. ft. of new experimental space. In this hall, 15 experimental stations will be installed over the next three years to provide new cold neutron experimental capability not currently available anywhere in the United States. A number of groups are involved in this effort, including the NIST Center for Analytical Chemistry and the Center for Atomic, Molecular and Optical Properties (CAMOP), Exxon Research and Engineering Co., Eastman Kodak Company, Sandia National Laboratory, the National Science Foundation, 
and several universities. The CNRF will be operated as a National Facility, with a large fraction of the experimental time allocated by a Program Advisory Committee.

Assessment Summary

Extended periods of reactor down time were necessary for construction of the cold neutron facility. Downtime was effectively used by the staff to perform reactor maintenance and upgrade. The staff members are to be commended for their excellent performance, which has brought them recognition with a Department of Commerce Silver Medal Award.

Good progress has been made on the CNRF. The offices in the guide hall building have been completed and are in use. Seven holes for the neutron guide tubes have been bored through the reactor containment building wall. Installation of the guide tube has begun and two new SANS instruments are under construction.

Research of very high quality was performed in a wide variety of areas. Highlights include multilayered magnetic materials involving rare earths: high Tc superconductors; dynamics of hydrogenous entities adsorbed on various materials; application of the maximum entropy technique to find the structure of macromolecules; the behavior of polymer blends, especially under shear. Development has continued on neutron devices and techniques such as supermirrors and spin polarizers.

The Panel is very favorably impressed with the operation of the Division. There appears to have been a remarkably smooth transition from the leadership of Dr. Robert Carter to that of Dr. J. M. Rowe, a fact which is a tribute to both men and to the administrative team. The Panel members commend all of those who have been responsible for the planning and construction of the new guide hall. A great deal of thought, care and foresight has gone into all aspects of its design.

\section{Nondestructive Evaluation}

Functions of the office

The office provides the national system for nondestructive evaluation (NDE) measurements needed in the manufacture and use of materials, components, and systems to assure reliability and enhance productivity. The office develops and provides NDE measurement standards and calibration services. It also conducts research to achieve a better understanding of the relationship between important materials processing or manufacturing characteristics and nondestructive evaluation methods and data.

Introduction

The NIST program in NDE addresses the most pressing national needs in NDE measurement science. Program results lead to better reproducibility and understanding of nondestructive measurements for quality control in manufacturing and for increased reliability of field inspection of in-service 
equipment. The major areas of scientific activity in the program include: acoustic emission, ultrasonics, eddy current devices, x-ray radiography, neutron and $x$-ray diffraction, small angle neutron scattering, magnetic measurements, optical scattering, dye penetrants, thermal wave imaging, and residual stress determinations.

This year marked the sixth year of definite progress towards reaching many of the objectives and goals as stated in the December 1984 Strategic Plan. This plan changed the major direction of the program to NDE for process control from NDE for in-service inspection. This plan, which should be viable well into the 1990s, involves a proposed major expansion of our activities into the broader arena of intelligent processing of materials.

The research efforts were focused this year, as they were the previous year, on four selected high-priority activities: NDE for Ceramic and Metal Powder Production and Consolidation, NDE for Formability of Metals, NDE for Composites Processing and Interfaces, and NDE Standards and Methods. This focused approach provides enhanced synergism between NDE research efforts and NIST efforts in materials science and engineering, and provides greater interactions with industry.

An industrial consortium, consisting of Crucible Materials, Hoeganaes, and General Electric, working with NIST, has successfully completed the second year of a three year program to develop intelligent processing technology for rapidly solidified metal powders. Progress continued towards developing a fundamental understanding of the liquid jet break-up leading to metal droplet formation. Noteworthy advances were again made in the joint effort between the Aluminum Association and NIST to develop an internal temperature distribution sensor for monitoring the extrusion of aluminum. Sensing techniques have been extended to thin, flat sections such as U-channels, Ibeams, and flat strip and sheets.

\section{Assessment Summary}

The professional staff in ONDE is very active in national societies and meetings, has sponsored numerous industry workshops and forums, has taken the leadership in developing national standards, and participates in internal planning with senior NIST scientists and engineers. Staff support of NDE activities in NIST is based upon well-described selection criteria, including national need, fit to NIST mission, fit to ONDE mission, quality of proposal and staff, organizational interest, and unique NIST facilities.

Great progress was made in the metal atomization system program toward an understanding of the liquid jet break-up leading to droplet formation and the development of a process model, the development of real-time methods for in situ sensing of droplet size and velocity, and development of an intelligent control system.

Measurement of the thermal diffusivity as a function of frequency was found to be a good technique to use for characterization of the extent of surface damage produced by machining of hot pressed silicon nitride ceramics. 
The eddy current work that is supported with the help of a research associate from the Aluminum Association presents the example of a good success story and illustrates an effective way to ensure technology transfer. The Panel finds that the efforts of ONDE in bringing such outside experts in to work with NIST scientists and engineers is outstanding and these efforts should be emphasized and supported at an increased level in the future.

\section{MSEL Initiatives}

The Panel was pleased with the progress achieved in both the Automated Processing of Materials Initiative and the Composite Initiative. Detailed reports of the significant achievements have been reported in other sections of this report and will not be duplicated here. The Panel recommends, though, that a formal report to the Panel on the progress achieved in an initiative and on the plans for future work be presented after completion of the third year of the initiative. Such a report for the Ceramic initiative should be made at the next panel meeting.

The proposed Electronic Packaging initiative is very timely. The planned industry workshop in the spring will undoubtedly help define the direction of this initiative. The Panel is, however, concerned that to be successful, such an initiative will have to look at the electronic packaging problem as a system problem. As such, the initiative will require the involvement of experts from throughout the NIST organization. The present discipline based organization of NIST may be a hamper to such a success and the formation of a project office such as ONDE might be necessary.

\section{MSEL Panel Concerns}

The Panel is concerned with the gradual increase of the percentage of funding coming from outside sources. For example, the Ceramics Division receives $50 \%$ of its funding from non NIST sources. The Panel believes that such outside funding should not exceed the 30 to $40 \%$ level. Increased outside funding is particularly deleterious to the role of NIST and MSEL as developer and keeper of standards. Such a mission, although of obscure appearance, is critically important to the U.S. economy. Without reference standards, not only can commerce not flow in a smooth and efficient fashion but research on new material systems can be delayed considerably.

The Panel is concerned with the large number of foreign guest scientists in relation to the new role of NIST as instrumental to the improvement of U.S. industry competitiveness on the world markets. The Panel recommends MSEL management to carefully analyze the benefit/risk associated with the present guest scientist program in relation to their impact on MSEL efforts to improve industry competitiveness.

The Panel is concerned with the situation that will occur at the Reactor Radiation Division when the 5 -year construction phase is finished and the facility goes fully into its user mode of operation. The RRD must be given the financial support to be able to run the user program in such a manner that users are given the assistance needed to enable them to make the most of their 
beam time while at the same time permitting the staff scientists to carry out RRD's own research program.

The Panel is concerned that MSEL and NIST do not have a clear intellectual property rights position. Patents and their management are one of the elements of competitiveness for an industry. The Panel feels that NIST and MSEL will find their technology transfer efforts with industry hampered by the lack of a patent portfolio. Patents and rewards to the inventors should become, in this new environment, a way of life for those involved in projects affecting industry. Licensing can be used as a tool to promote an industry in the world market place if proper patenting strategy has been developed on a worldwide basis. The panel recommends that a concerted effort be initiated to develop such a strategy. Perhaps help from some international industrial partners could be sought in this endeavor.

The Panel commented on the management structure of the MSEL, and suggested that an evaluation of the role of the office of Nondestructive Evaluation would be in order. Consideration should be given to broadening the role of this organization and forming a Program office to assist in coordination of major efforts involving more than a single Laboratory at the Institute. Such an office would be charged with the responsibility to foster interdivisional and interdisciplinary programs. 


\section{NIST AND MSEL \\ ORGANIZATION CHARTS}





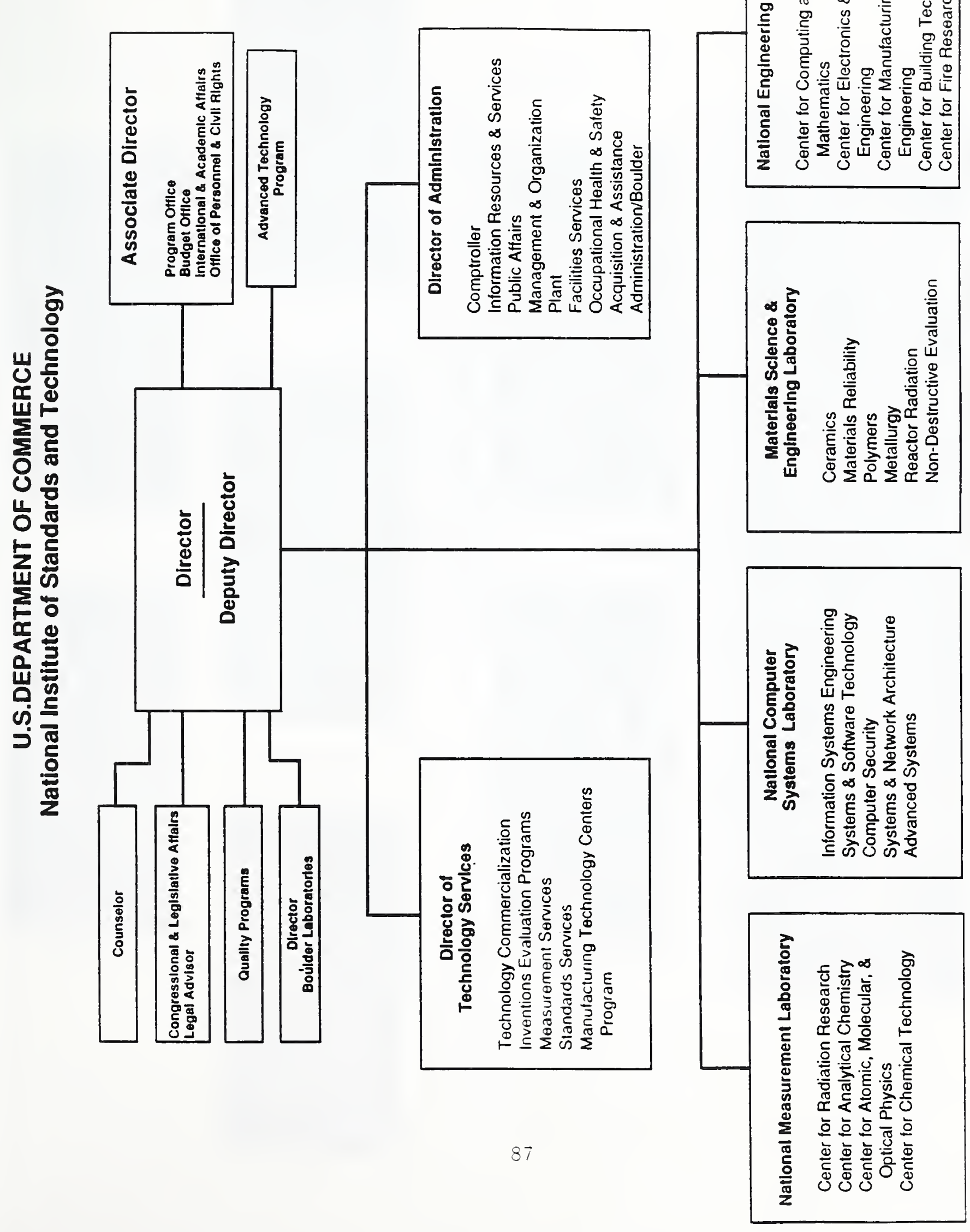



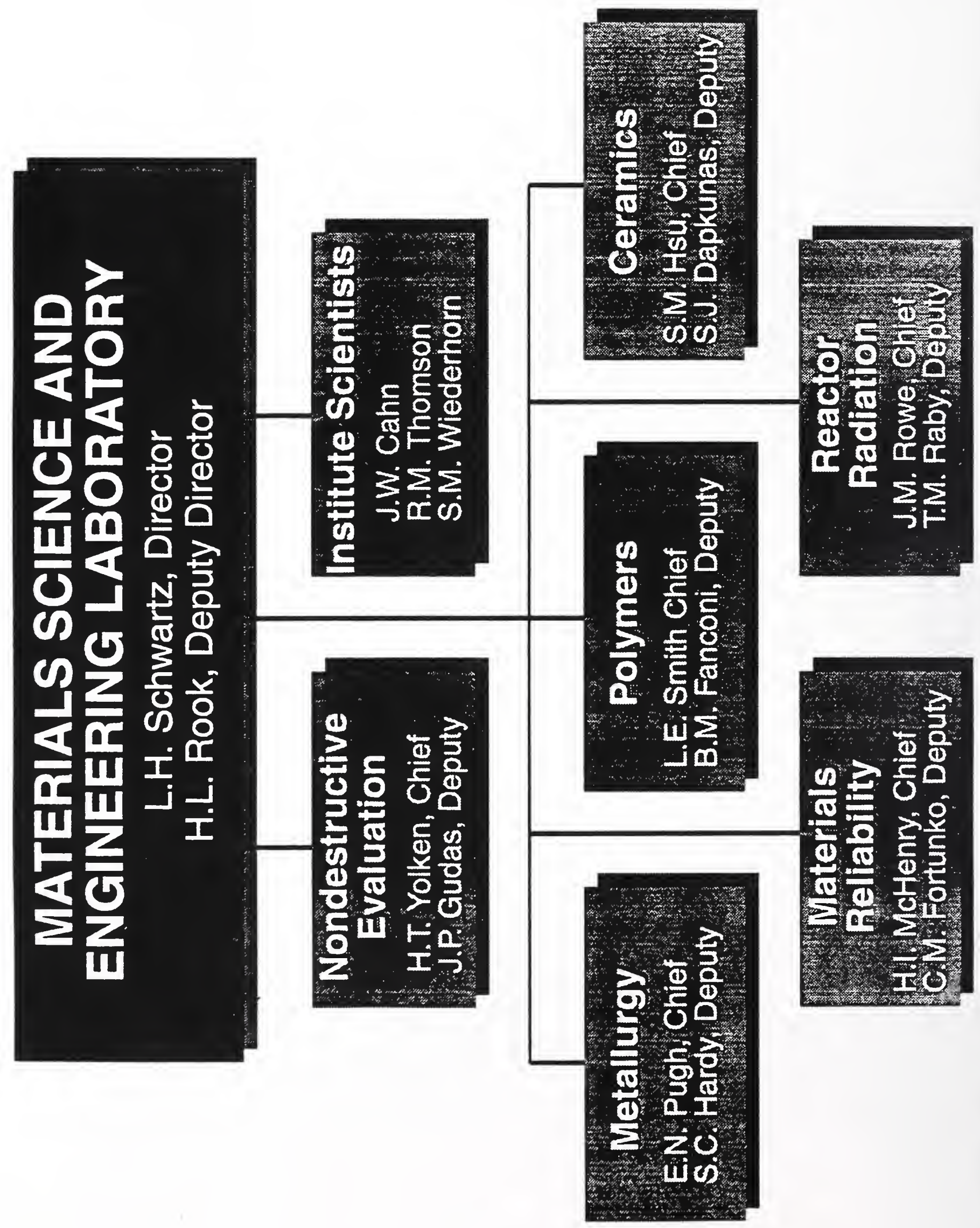


\section{MATERIALS SCIENCE AND ENGINEERING LABORATORY}

Develops and maintains the scientific competences and experimental facilities necessary to provide the Nation with a central basis for uniform physical measurements, measurement methodology, and measurement services fundamental to the processing, characterization, properties and performance of materials, and to other essential areas in materials science; provides government, industry, universities, and consumers with standards, measurement methods, data, and quantitative understanding concerning metals, polymers, ceramics, composites, optical materials, and nonequilibrium materials; characterizes the structure of materials, chemical reactions, and physical properties which lead to the safest, most efficient uses of materials, improve materials, technologies, provide the bases for advanced material technologies in basic and hightechnology industries; obtains accurate experimental data on behavior and properties of materials under service conditions to assure effective use of raw and manufactured materials, provides technical information such as reference data, materials measurement methods, and standards to processors, designers, and users for selection of cost-effective combinations of materials, processes, designs, and service conditions; uses the unique NIST reactor and cold neutron research facilities to develop neutron measurement methodology, develop sophisticated structure characterization techniques, reference data, and standards; participates in collaborative efforts with other NIST organizational units in the interdisciplinary developments in materials science; and disseminates generic technical information from the divisions to private and public sector scientific organizations through special cooperative institutional arrangements and through conventional distribution mechanisms. 



\begin{tabular}{|c|c|c|}
\hline \multirow[t]{4}{*}{$\begin{array}{l}\text { NIST-11MA } \\
\text { (REV. 3-0) }\end{array}$} & \multirow{4}{*}{$\begin{array}{l}\text { U.S. DEPARTMENT OF COMMERCE } \\
\text { NATIONAL INSTITUTE OF STANDARDS AND TECHNOLOGY } \\
\text { BIBLIOGRAPHIC DATA SHEET }\end{array}$} & $\begin{array}{l}\text { 1. PUDUCA TIOM OA MEPOAT MUMLEA } \\
\text { NISTIK } 4392\end{array}$ \\
\hline & & 2 PERFOAMIMO ORQWIEATON REPOAT MULEER \\
\hline & & 3. PUUCATIOM DATE \\
\hline & & December 1990 \\
\hline
\end{tabular}

4. TITI AND SUETITI

MSEL Annual Report, 1990

5. AUTHOR(S)

Dr. Lyle H. Schwartz

6. PERFORMINO ORQNMIZATION (H JOWT OR OTHER THAM NIST, SEE IMSTRUCTONS)

U.S. DIPNATMET of Coumence

MATONAL INSTITUTE OF STANONAS AND TECHNOLOOY

CNTHEAsEuna, mo 2000

7. CONTRAT/ORANT NUMEES

Q. TYFE OF REPORT AMD PERIOD COVEAED

$10 / 1 / 89$ to $10 / 1 / 90$

9. SPONSORIMG ONQNYZATION MWE NMO COMPUT NOONESS (STAET, CTY, STATE, ZIP)

National Institute of Standards and Technology

Materials Science and Engineering Laboratory

Gaithersourg, MD 20899

10. SUPPLIMETTAY NOTES

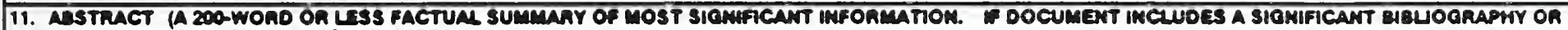
UTERATUAE SUAVT, MaNTiON IT MERE)

The 1990 Annual Report was prepared for the NAS-NRC Board of Assessment of the Materials Science and Engineering Laboratory. This volume contains background information on resources, activities, and representative highlights of the Laboratory.

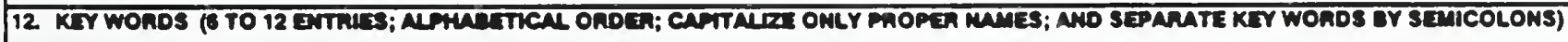

Activities; highlights; Materials Science and Engineering Laboratory; National

Institute of Standards and Technology; resources; review

\section{AVALNHTYY}

\section{UMunmed}

$\mathrm{x}$

FOR OFFICLL DISTMLUTIOH. DO MOT RELEASE TO MATIOMLL TECHMICAL INFOAMATION SEAVICE (NTTS).

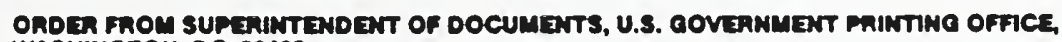
WASHINOTON, DC 20402

ORDER FROM MATIONAL TECHNICAL IMFORLATION SEAVCE (MTIS), SPRINOFIELD, VA 22161.
14. MUMLEN OF PRINTED PAOES

79

15. Pnाc: 


